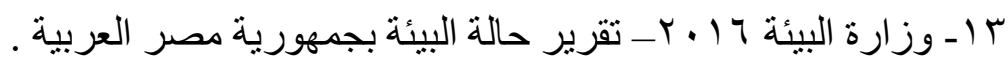

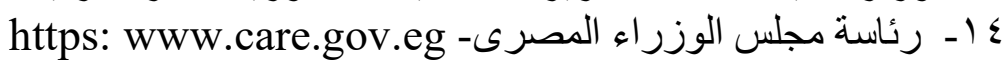

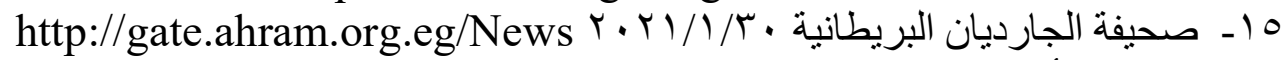

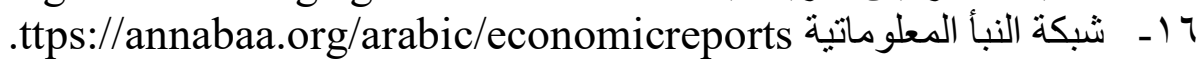

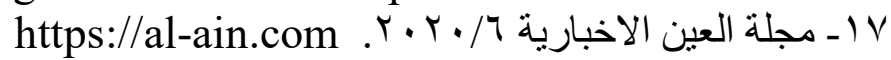

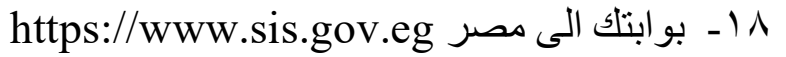

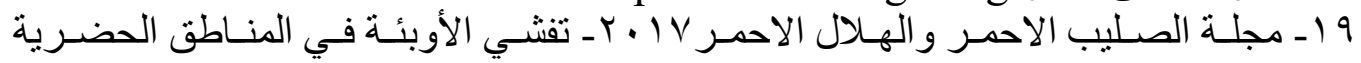
https://www.rcrcmagazine.org

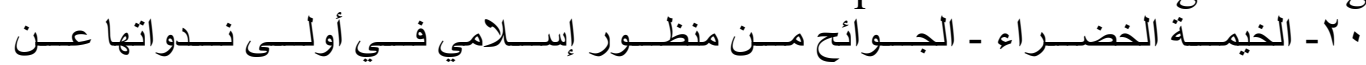
https://lusailnews.net/article/society/qatari بعد

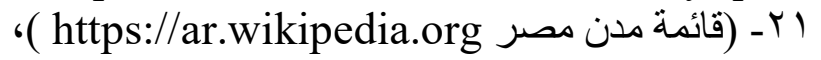

.https://www.maspero.eg - rr

. https://ar.wikipedia.org/wiki $-r r$ 


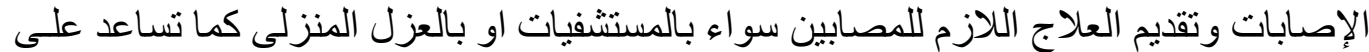

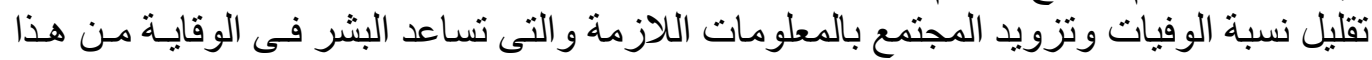
الوباء و العلاج اللازم لله

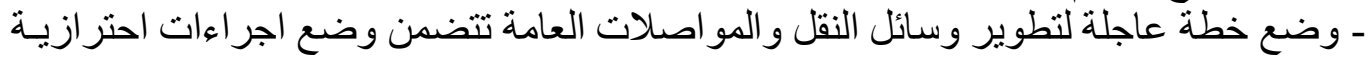

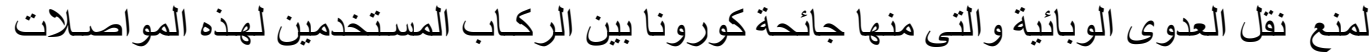
نتيجة الزحام الثديد للركاب داخل هذه المركبات

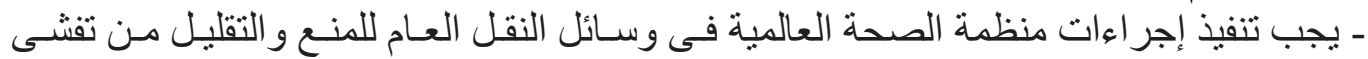

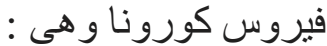
ا ـ إرتداء الكمامة (الماسك) لأنها أول عو امل منع إنتقال العدوي، خاصة فى حالـة وجـود تـز احم شديد داخل وسيلة المو اصلاء العات.

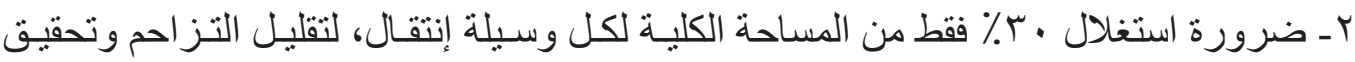

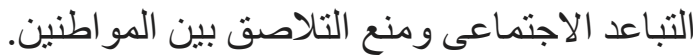
بـ تطهير ورش كل وسائل المو اصلات بالمطهر ات وتنظيفها جيدًا بعد نهاية كل رحلة.

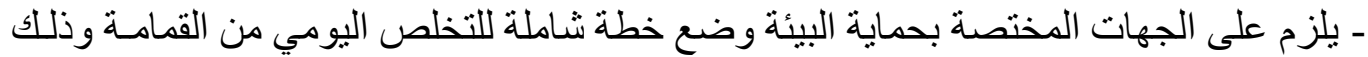
من خلال أسس تخطيطية تؤخذ فى الإعتبار عند وضع المخططات التفصيلية مع دفن هذه القمامة

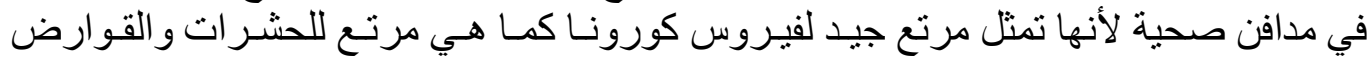

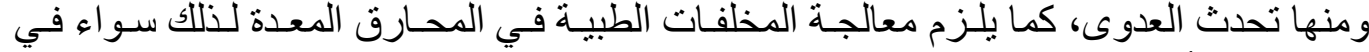
المستشفيات أو في محارق خاصنة

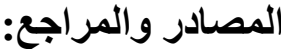
ا ـ النصر اوي، سلطان جاسم ـ الجوائح عبر التاريخ و الاقتصاد الكليـ كلية الإدارة والإقتصاد ـ http://business.uokerbala.edu.iq جامعة كربلاء

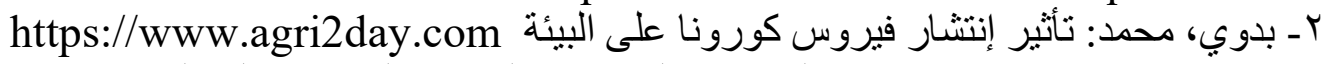
r- - حسن، غاده فاروق- تقييم دور الفراغات العمر انية بالمناطق السكنية ــلية الهندسة -جامعة

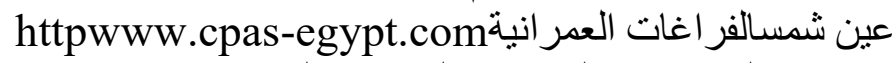

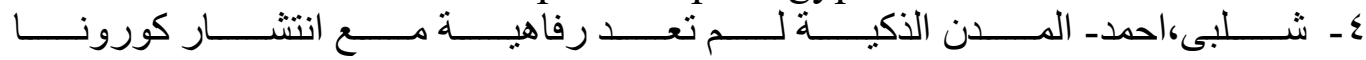
https://www.almasryalyoum.com ○ـ عبد الرحمن، محمد وأخرون (2019) الكثافة السكانية فى المدينة المصرية بين الحاضـر والمستقبل 39 engineering Research journal vol .no

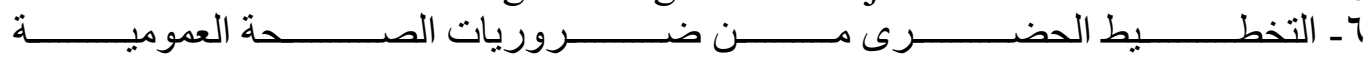
ttps://www.who.int/mediacentre/news/releases/2010 Vـ تلوث الهو اء عبء صحي للمصريين يزيد من مخاطر فيروس كورونا المستجد. https://eipr.org

ᄉـ المخطط الاستر اتيجى العام لمدينة دمنهور - الحسابات من الصورة الفضائية للمدينة بو اسطة الباحث. 9ـ الجهاز المركزى للتعبئة العامة والإحصاء ـ فيروس كورونا في مصـر در اسـة استكثـافية ـ سبتمبر • r r. r

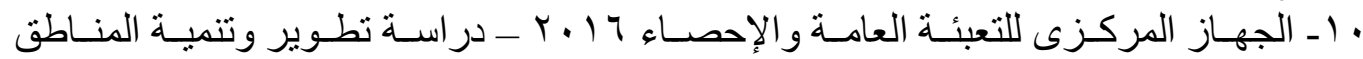

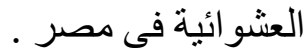

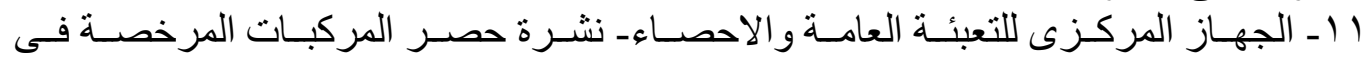
. $Y \mid V / T / Y)$

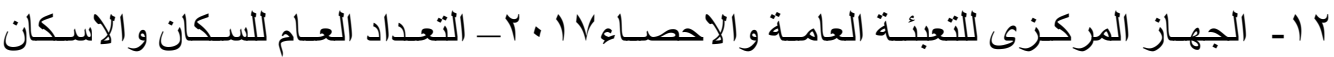


ـ تعتبر وسائل النقل و المو اصلات العامة بوضعها الحالى تمثل خطر ا كبير ا على المو اطنين حيث

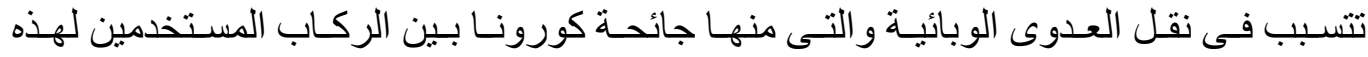

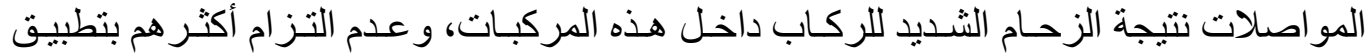

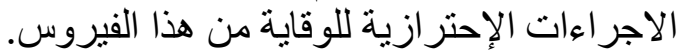

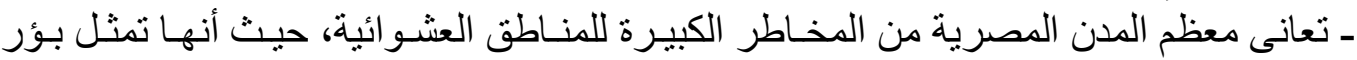

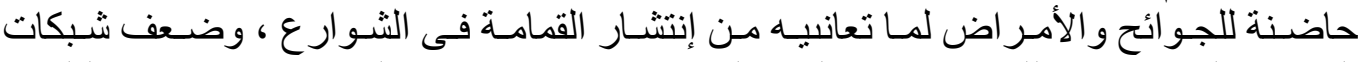

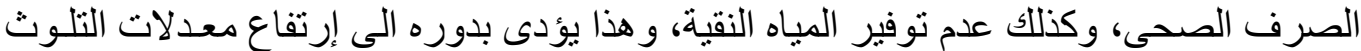

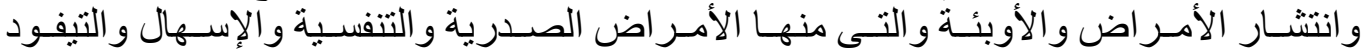
والنز لات المعوية و غير ها من الأمر اض اضل المعدية.

التوصيات : التز

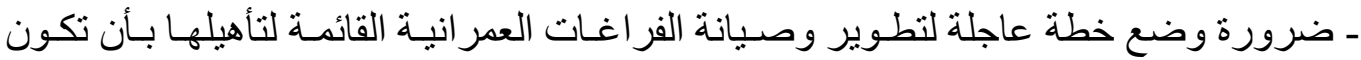

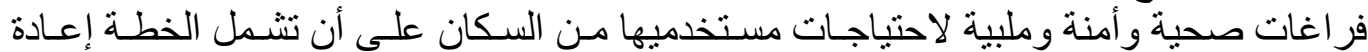

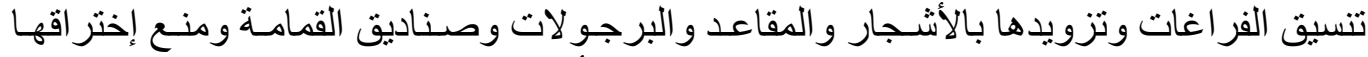

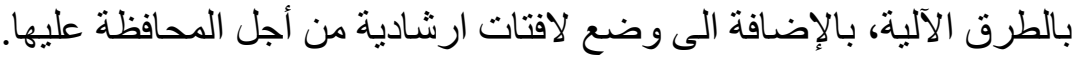

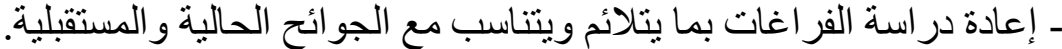

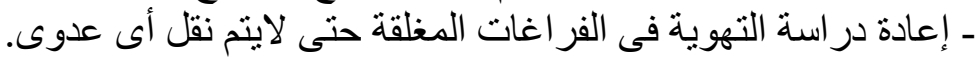

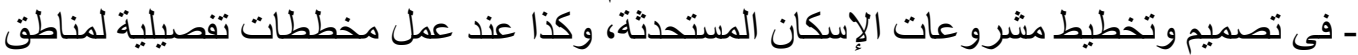

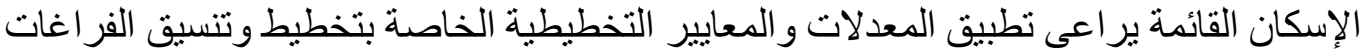

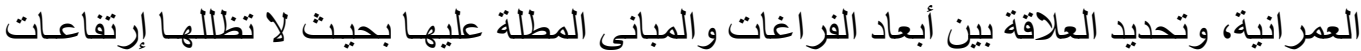

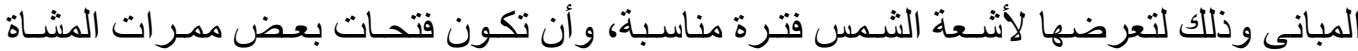

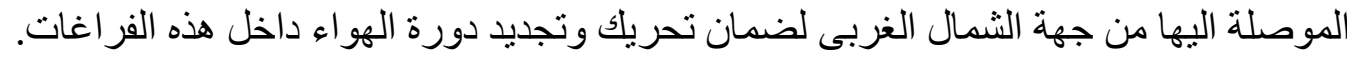

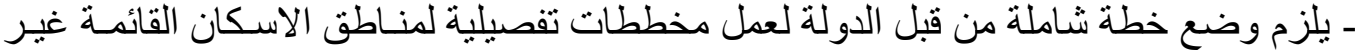

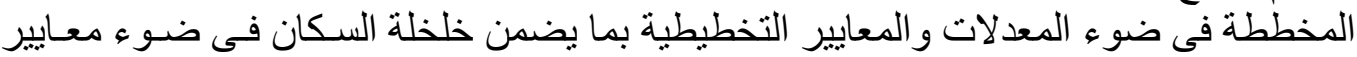

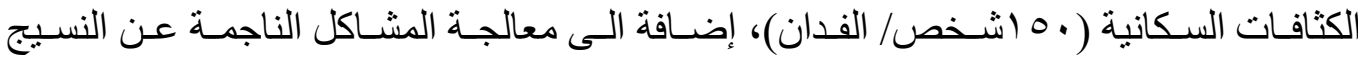

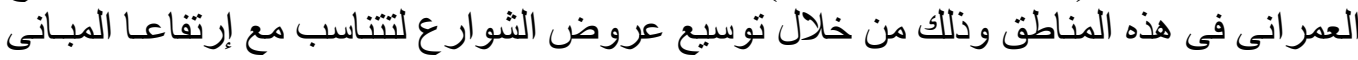
المطلة عليها وخلق فر اغات عمر انية مو اكبة لظروف خلف الفئ البيئة العمر انية المحيطة.

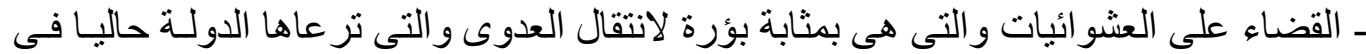
القضاء على مثل هذه العشو ائيات.

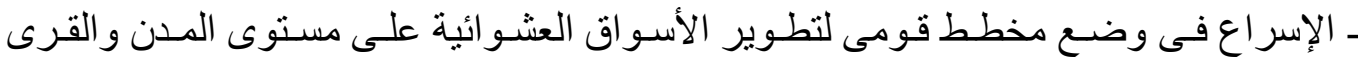

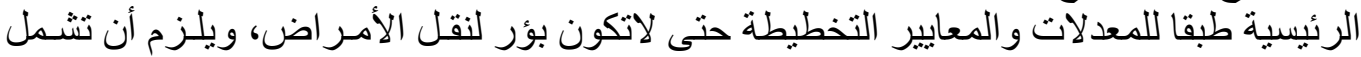

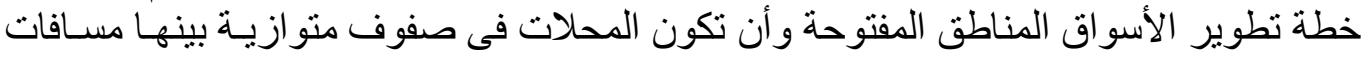

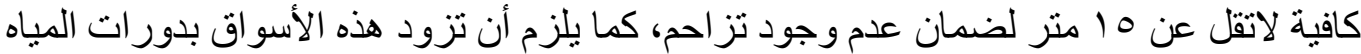

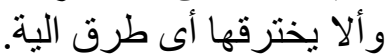

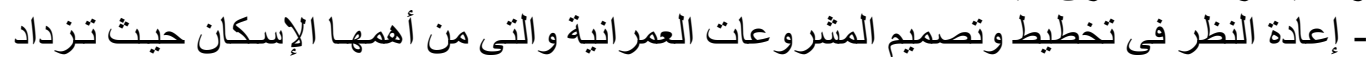

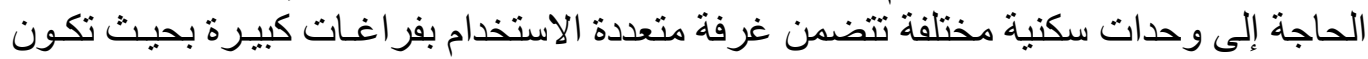

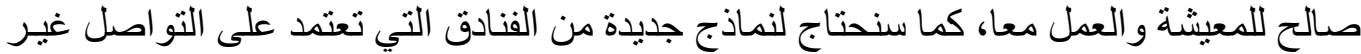

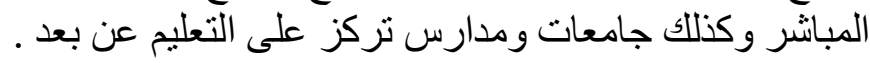

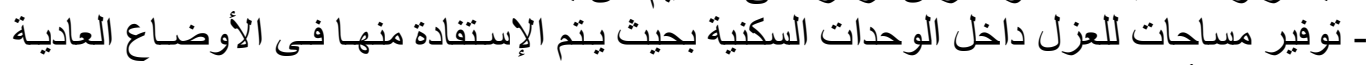

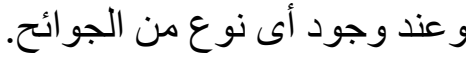

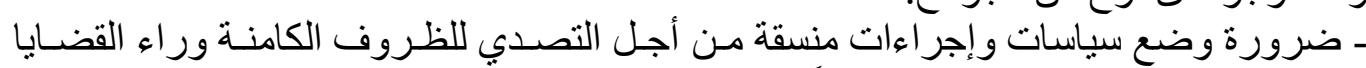
الصحية الرئيسية القائمة في المدن حالياً.

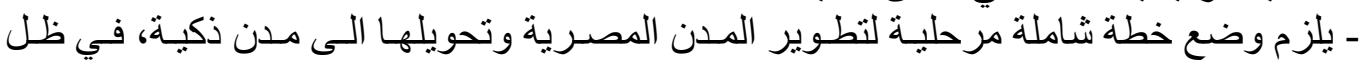

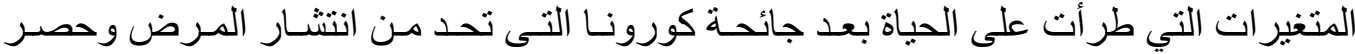




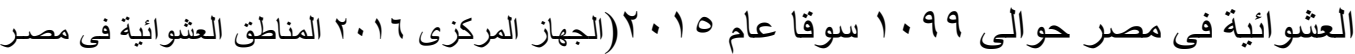

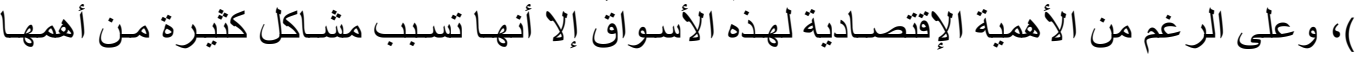

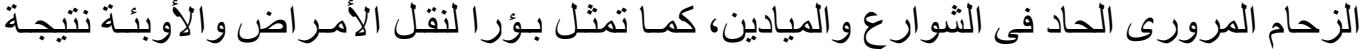

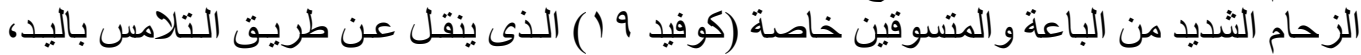

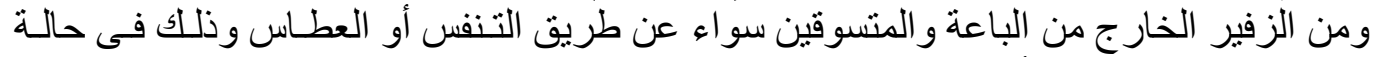

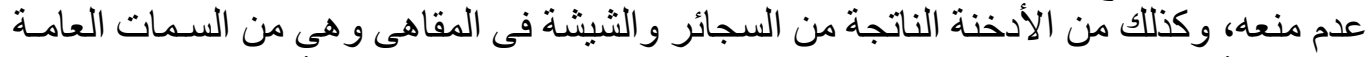

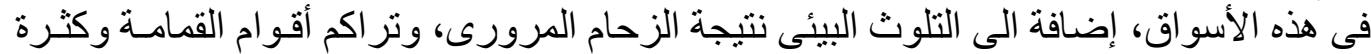

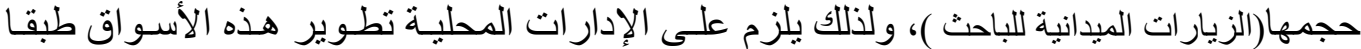

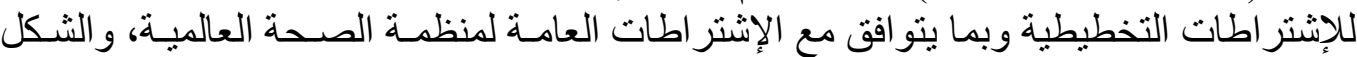

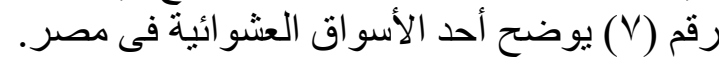

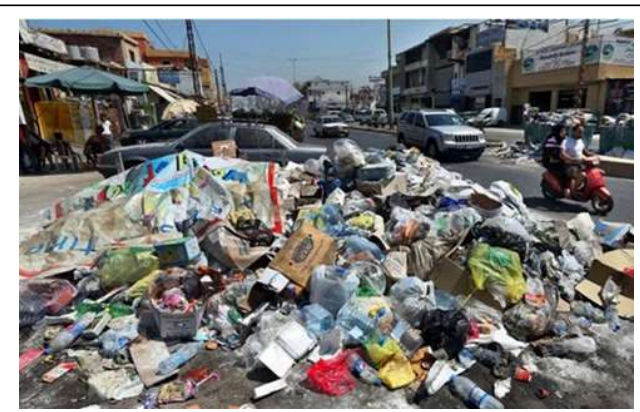

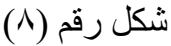
تفاقم مشكلة القمامة: لقد لعبت الزئ الزيادة السكانية

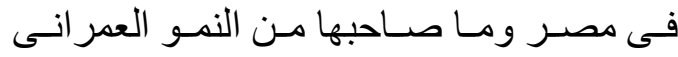

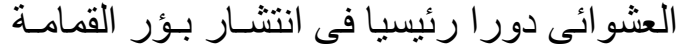

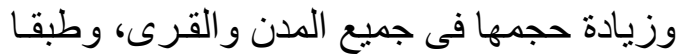

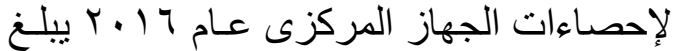

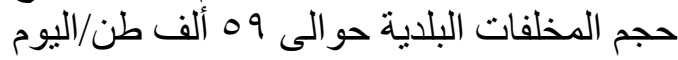
و هو مايعادل نحو r r مليون طن سنويا، ويقدر

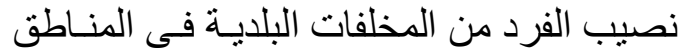

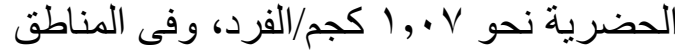

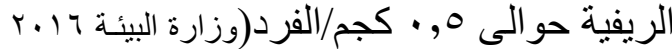

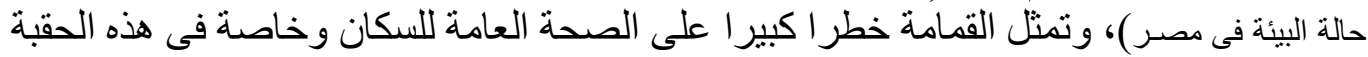

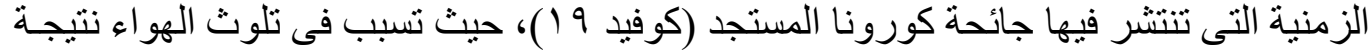

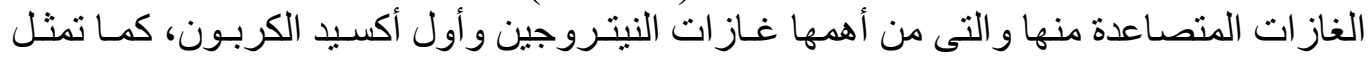

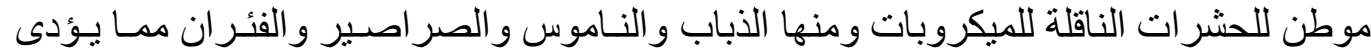

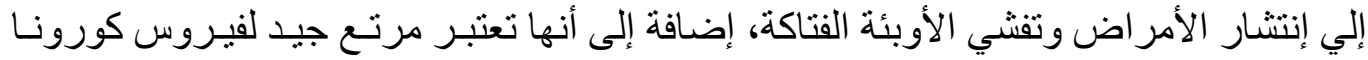

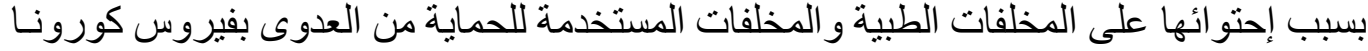

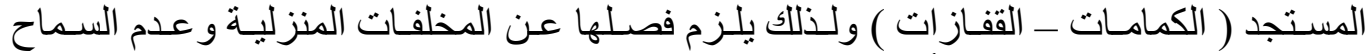

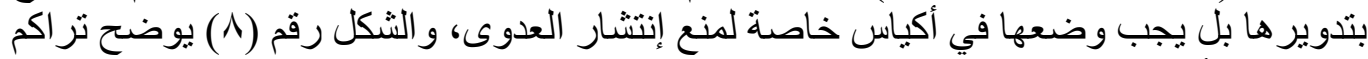

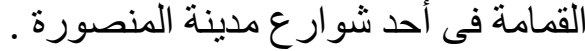

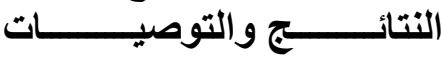

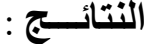
ــ المدن المصرية غير قادرة على الصـمود فيى مواجهـة الجـوائح والأوبئسة وتحوى بـين طياتهـا

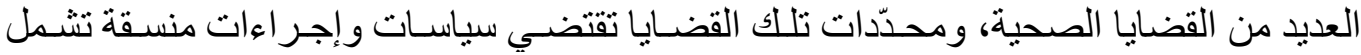

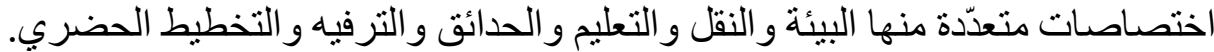

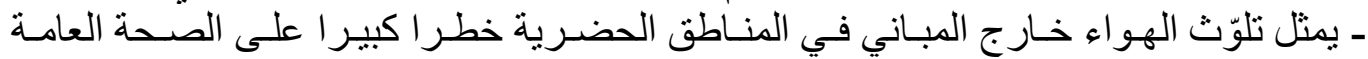

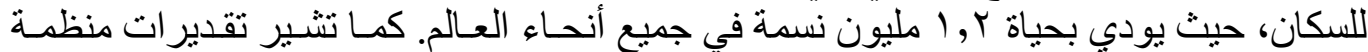

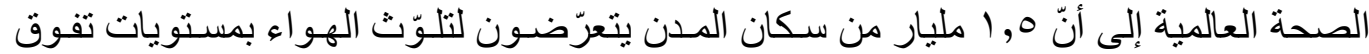

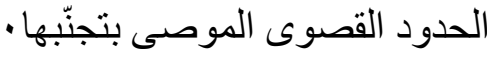

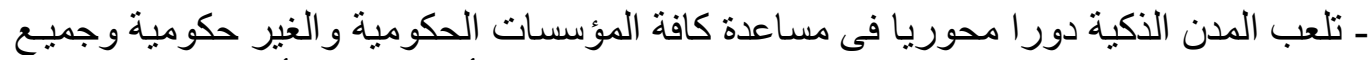

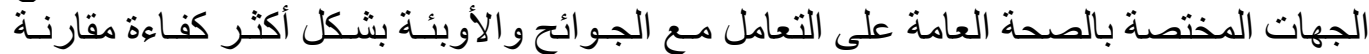

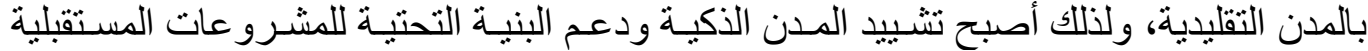
بالتكنولوجيا أمر ا ضروريا، في ظل المتغير ات التي طر أت على الحياة بعد جائحة كورونا. 
السكانية فى بعض دول العالم ففى دولة اليابان بلغ متوسط الكثافة السكانية فى المنـاطق المأهولــة

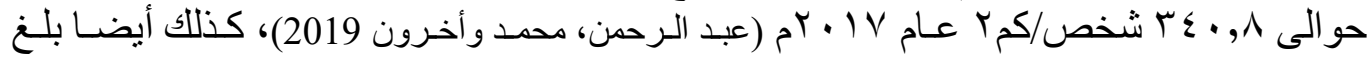

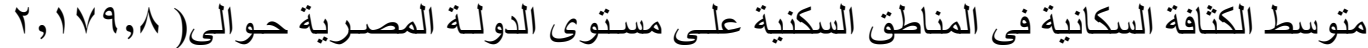

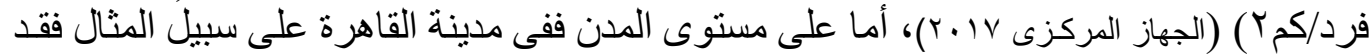

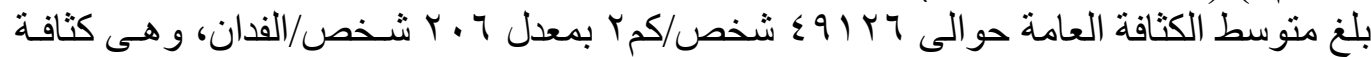

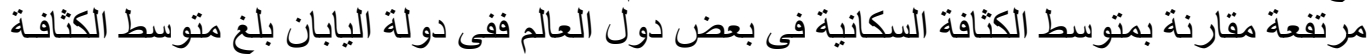

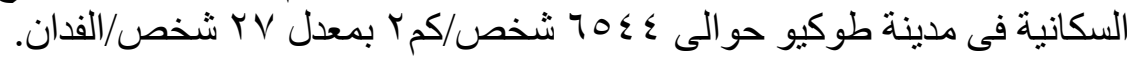

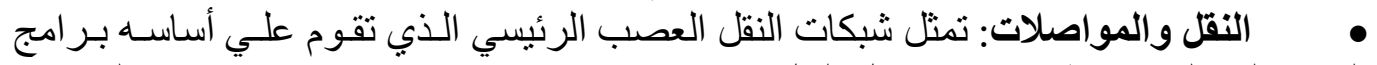

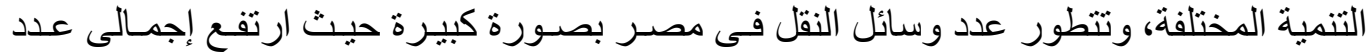

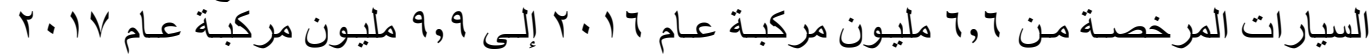

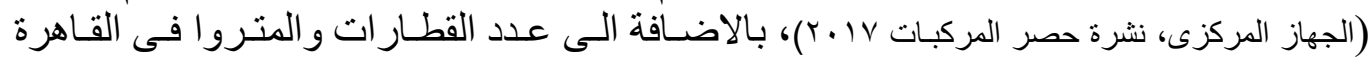

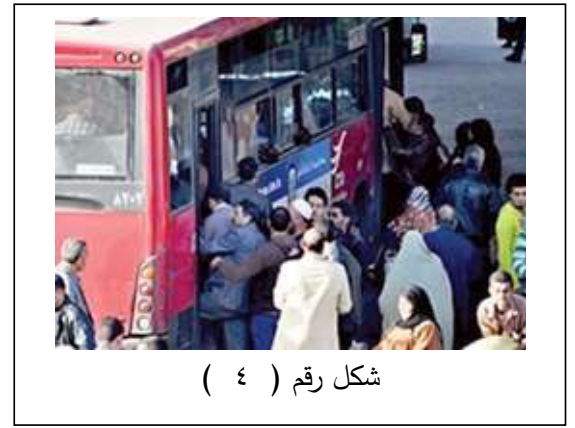

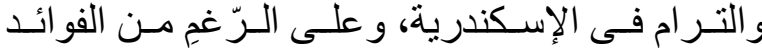

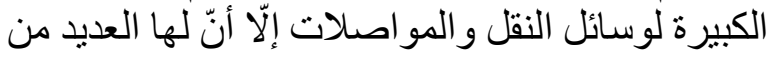

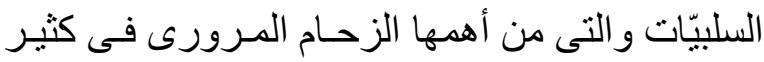

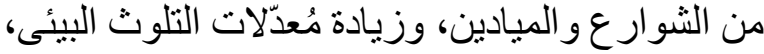

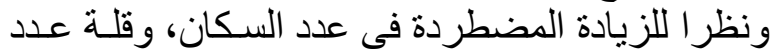

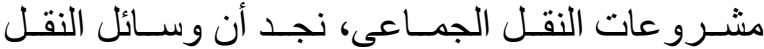

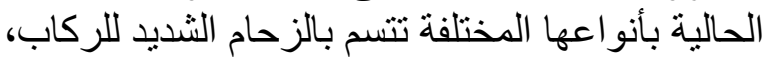

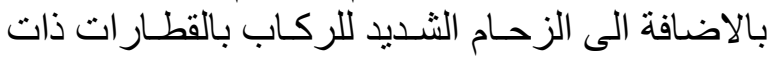

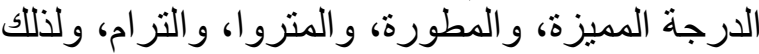

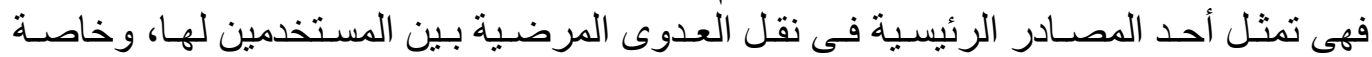

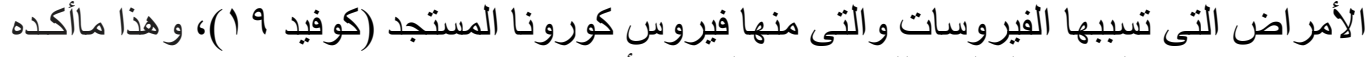
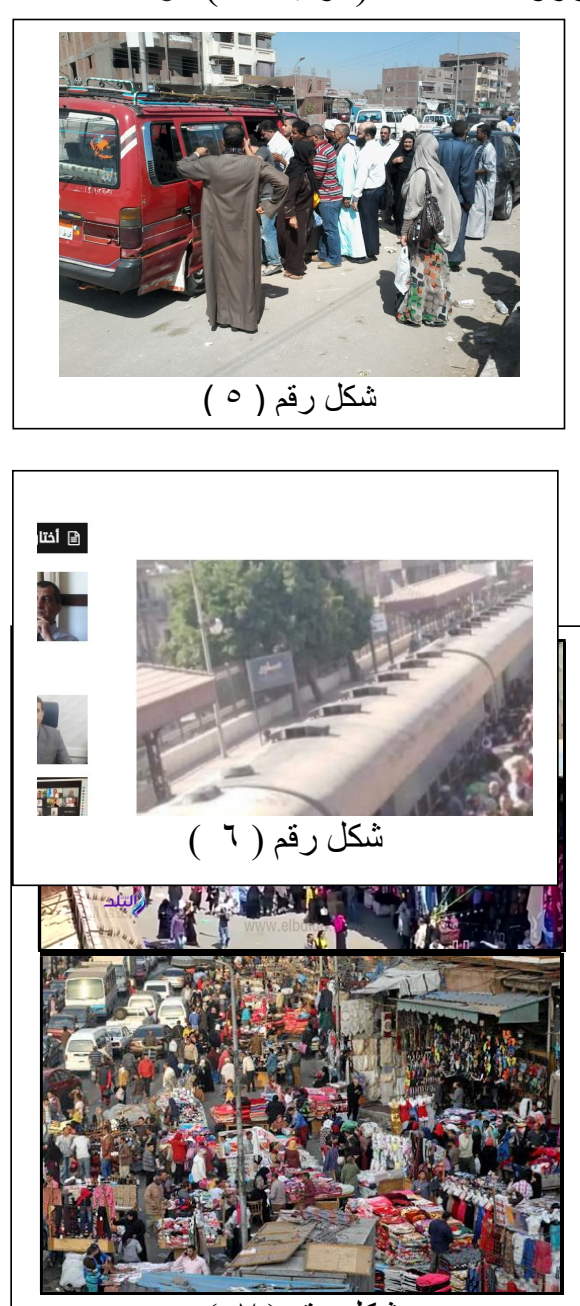

شكل رقم ( V)

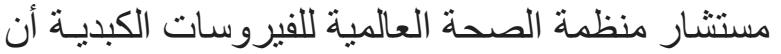

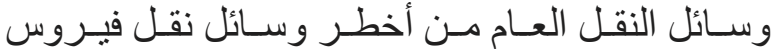

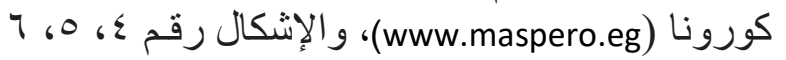

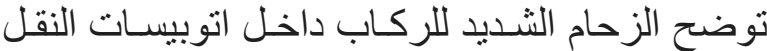
الجماعى، و مشروع السر فيس، و القطار ات.

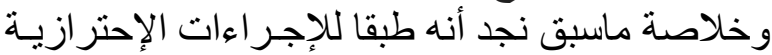
التى أعدتها منظمة الصحة العالمبة للوقابة مـن جائحسة

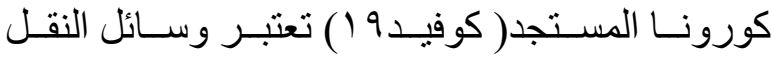
و المو اصلات العامة بوضعها الحالى تمثل خطر ا كبيرا

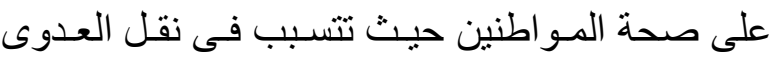

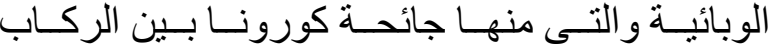
المستخدمين لها، إضافة الى أن بعض هذه المركبـات التهات غير صالحة للإستخدام لسوء حالتها الفنية. الأسواق التجارية العثـوائية: تنتشـر هـذه الأسـواق

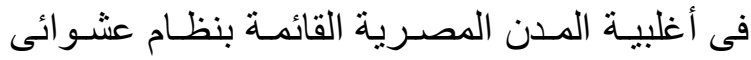

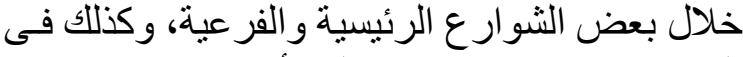

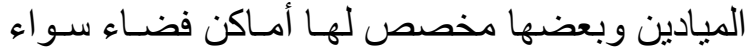

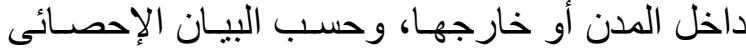

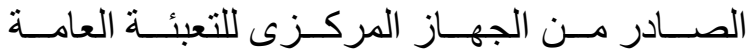

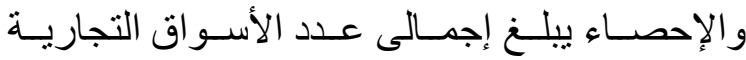




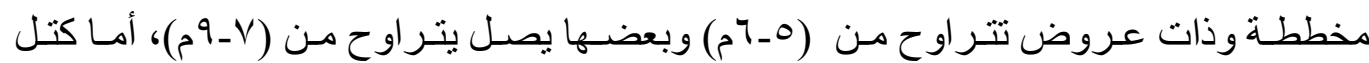

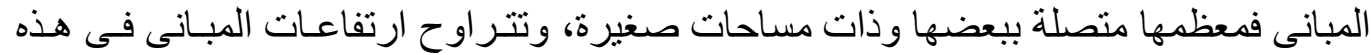

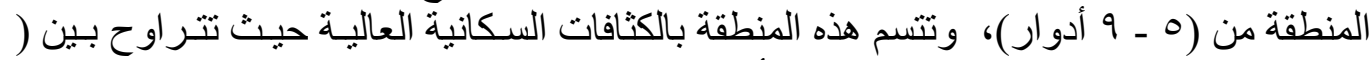

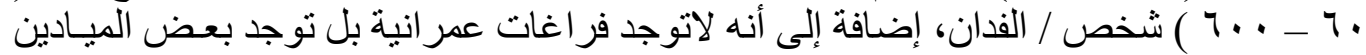

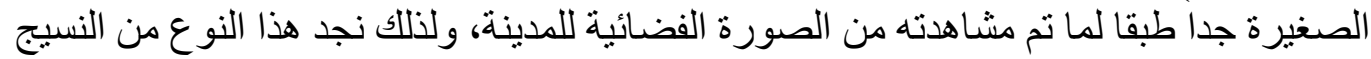

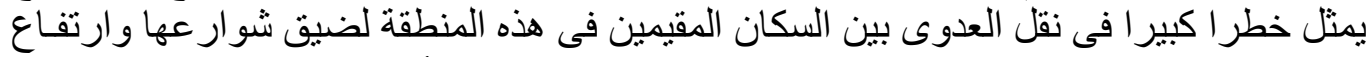

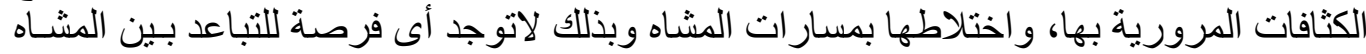

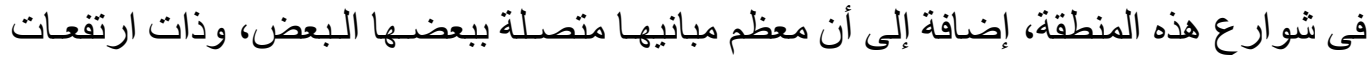

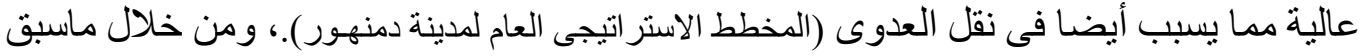

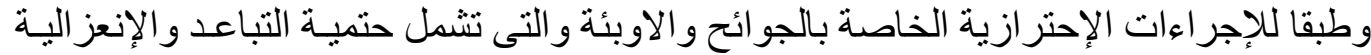

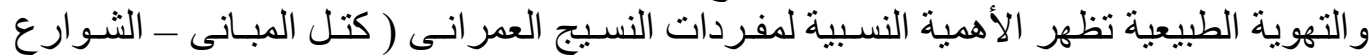

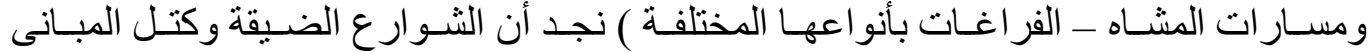

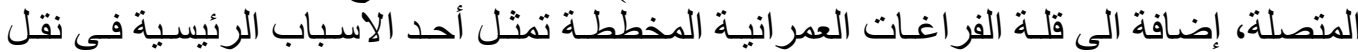
العدوى الوبائية بين السكان.

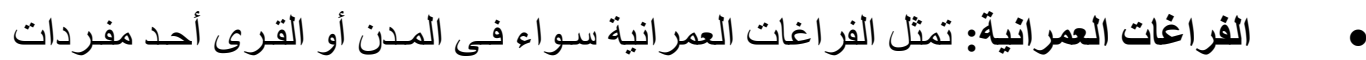

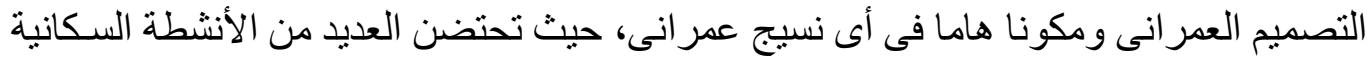

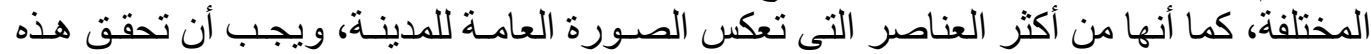

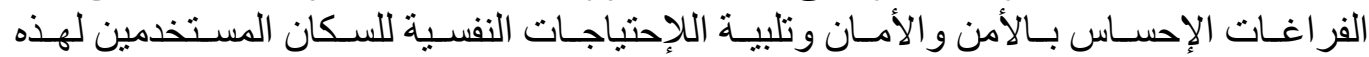

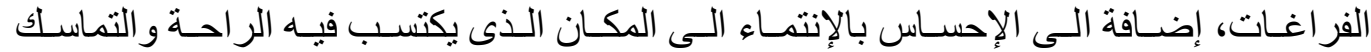

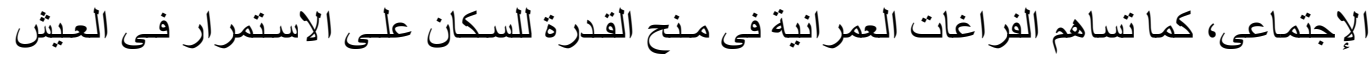

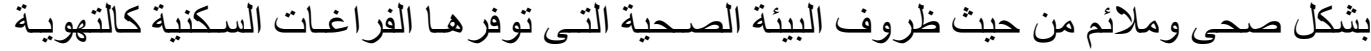
و البيئة النظيفة و المسطحات الخضر اءت اءت (حسن، غاده فاروق).

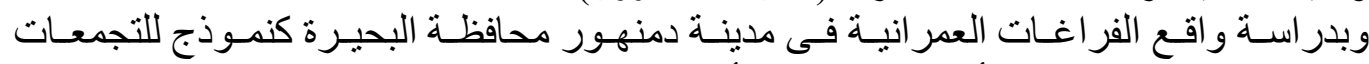
العدر انية فى مصر تلاحظ أنها شبه مختفية، أما القائم منها فيعانى مـن تدهور خطير في بيائتها

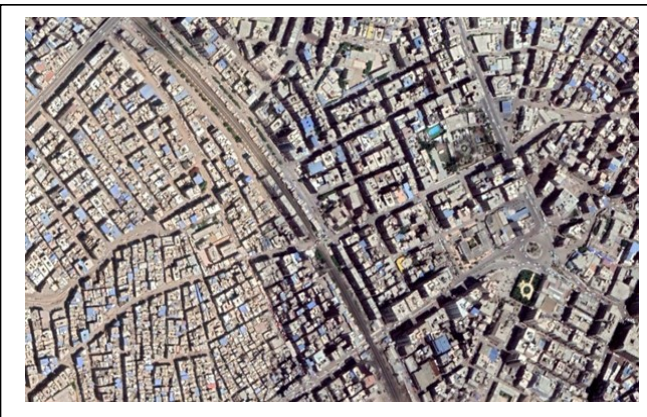

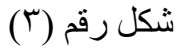

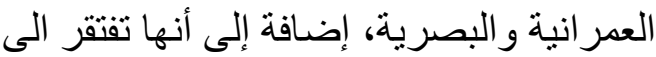

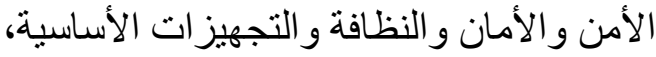

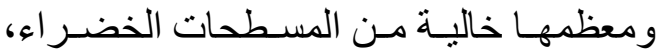

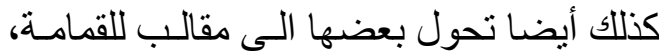

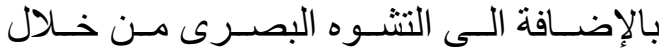

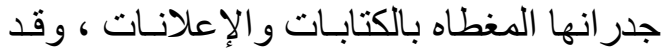

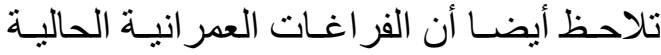

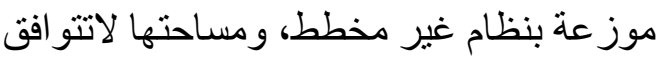

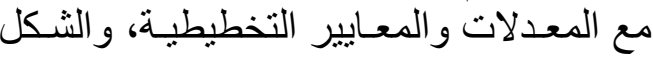

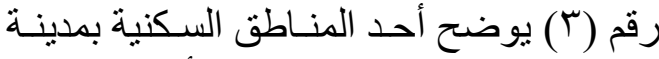

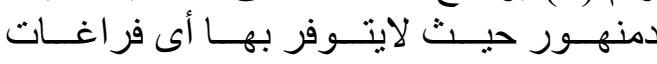
عمر انية.

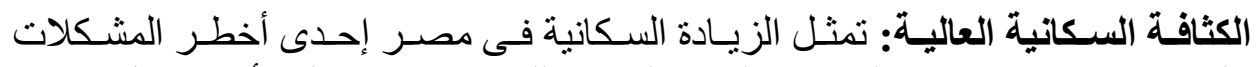

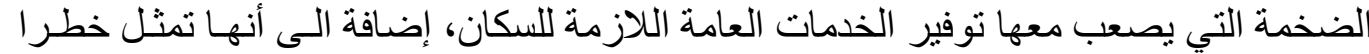

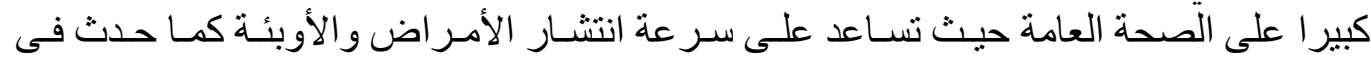

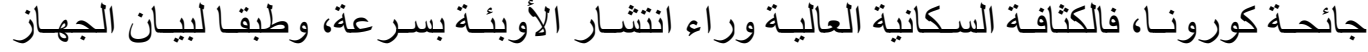

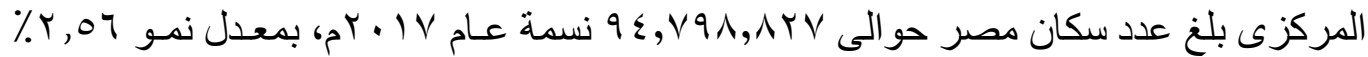

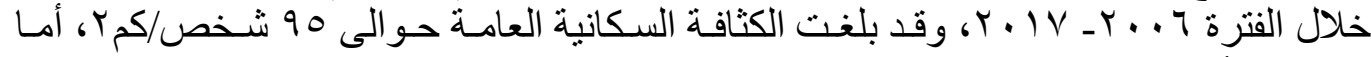

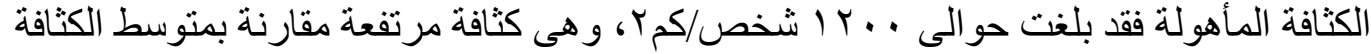


وتتصف هذه المناطق بارتفاع الكثافة السكانية وكبر حجم الأسرة حيث بلغ متوسط حجم الأسـرة

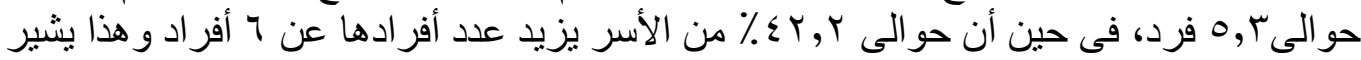

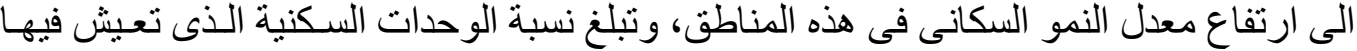

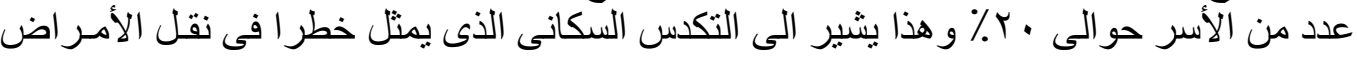

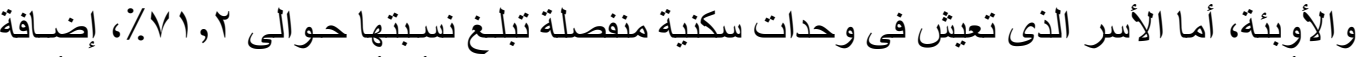

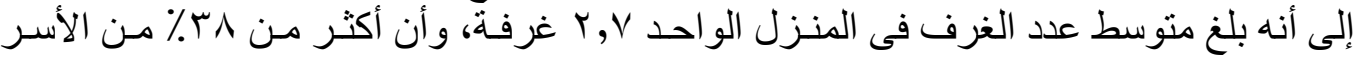

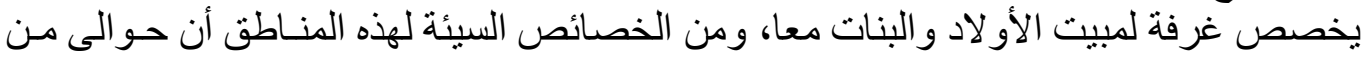

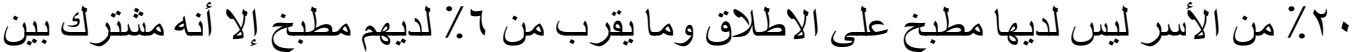

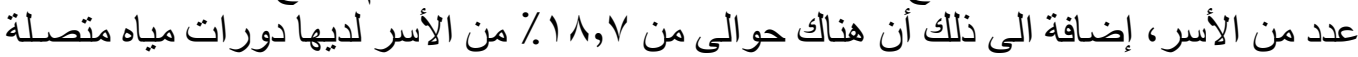

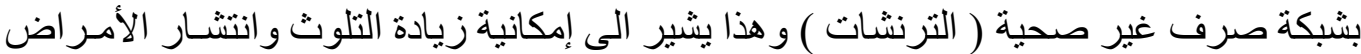

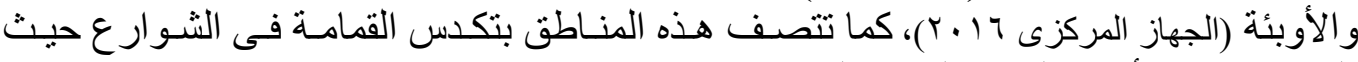

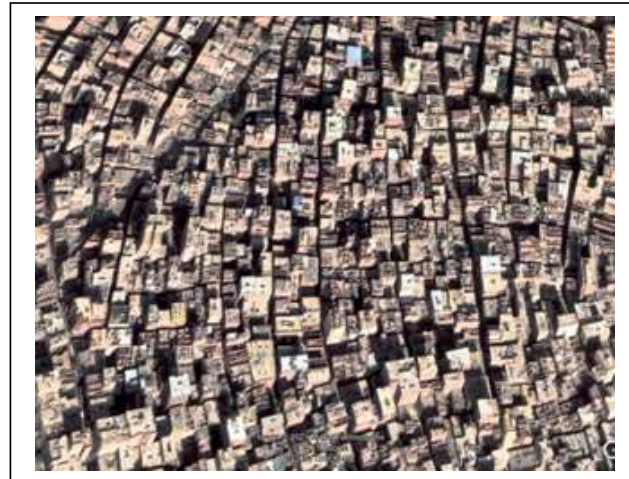

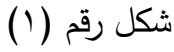

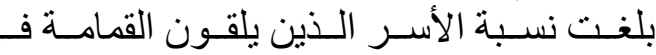

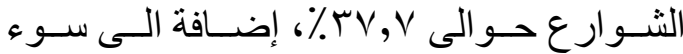

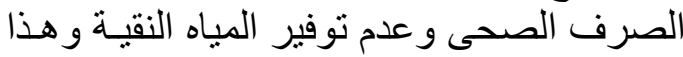
يؤدى بدوره الى ارتفاع معدلات التلوث و انتئنار

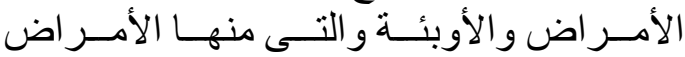

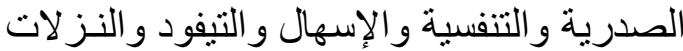

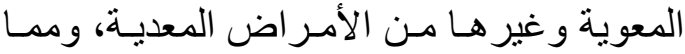

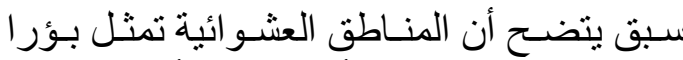

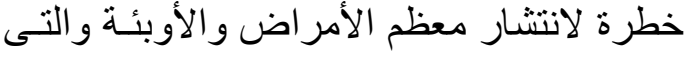

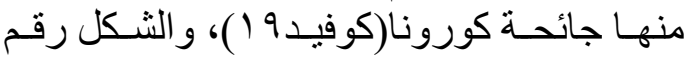

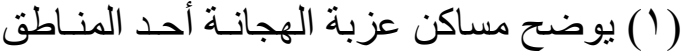

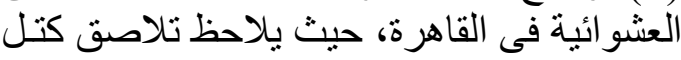

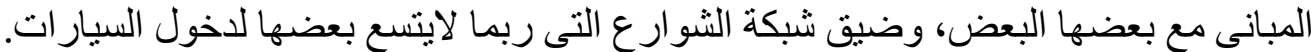

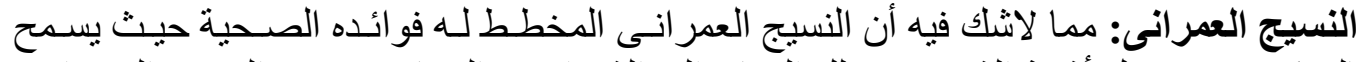

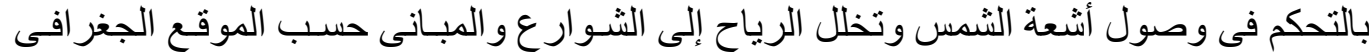

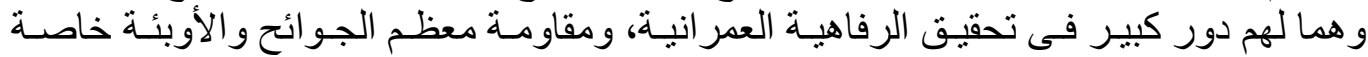

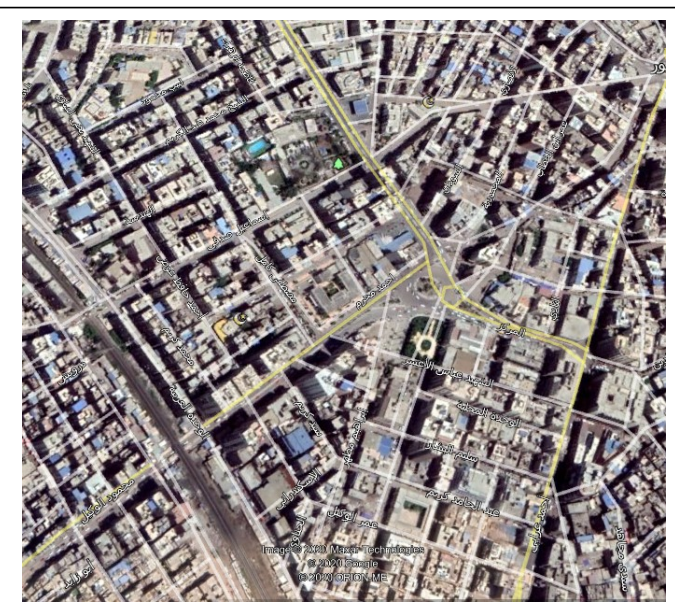

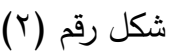

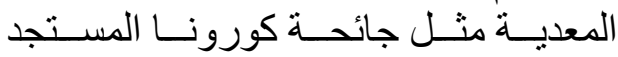

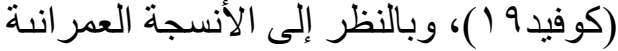

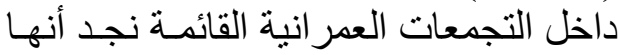

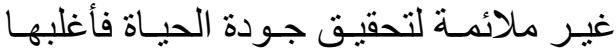

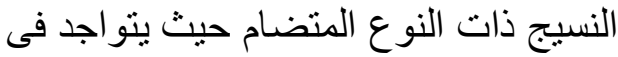

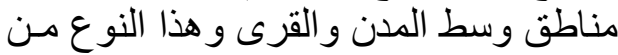

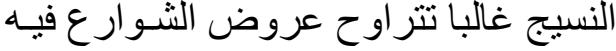

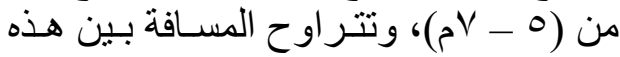

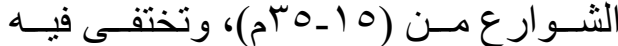

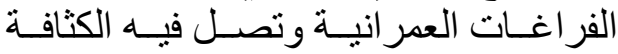

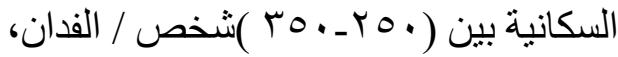

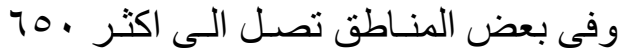

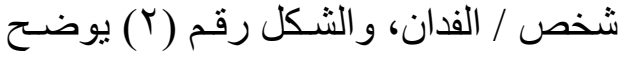

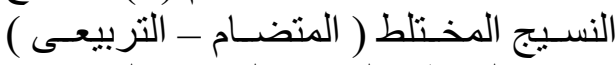

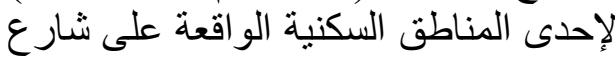
الجيش المصرى بمدينة دمنهور عاصمة محافظة البحيرة، ويتبـين مـن الثـكل أن الثـوارع عير 


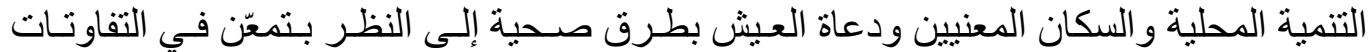

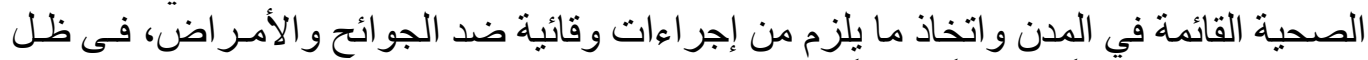

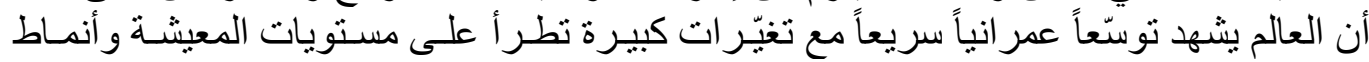

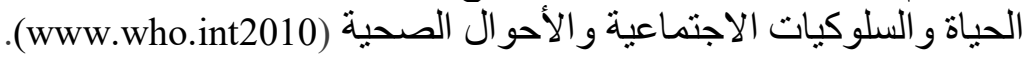

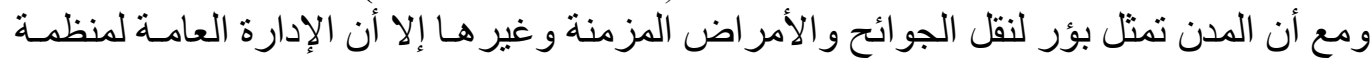

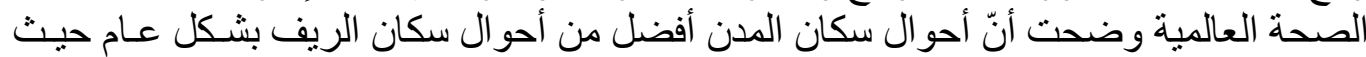

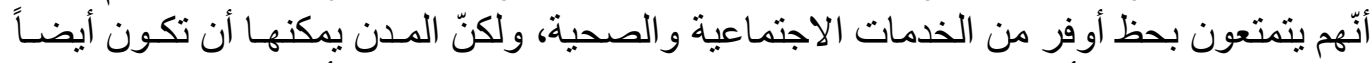

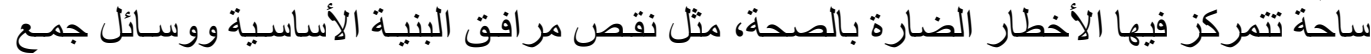

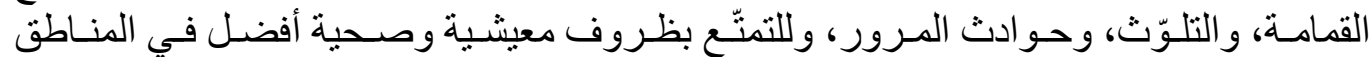

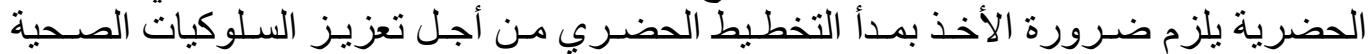

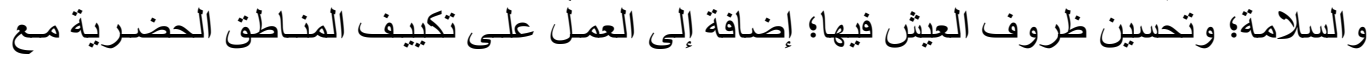

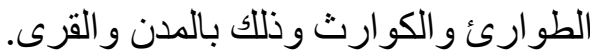

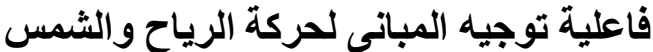

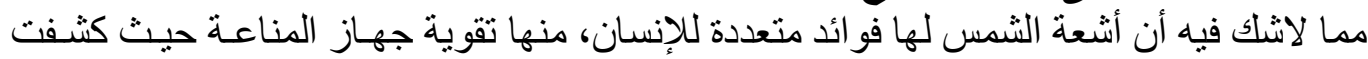

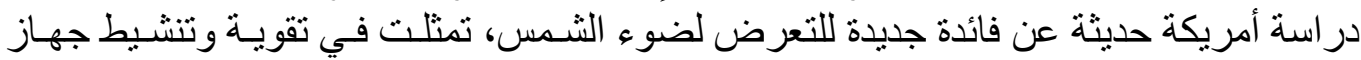

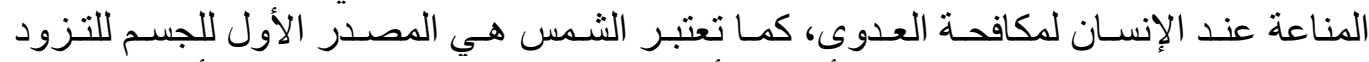

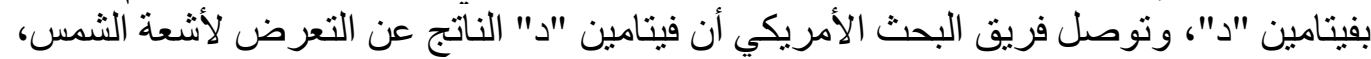

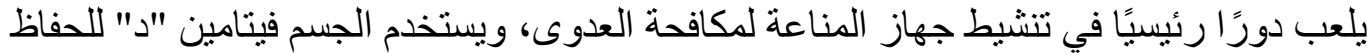

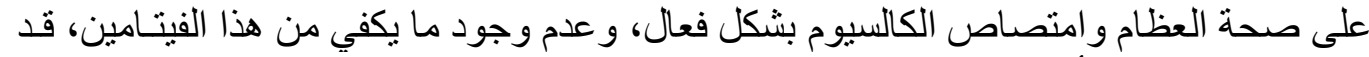

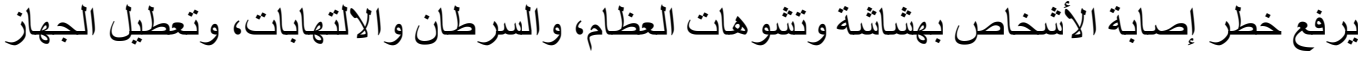

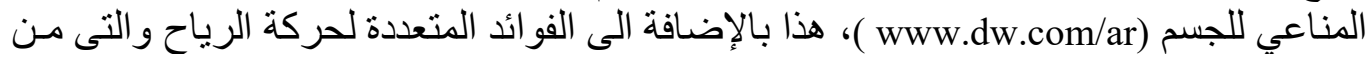

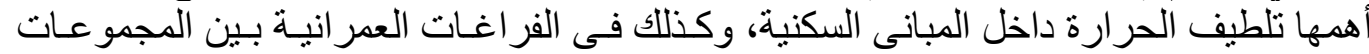

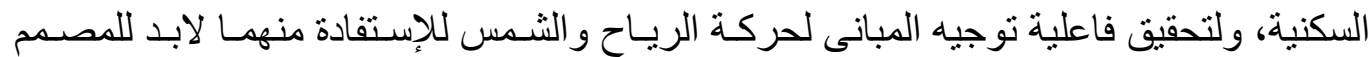

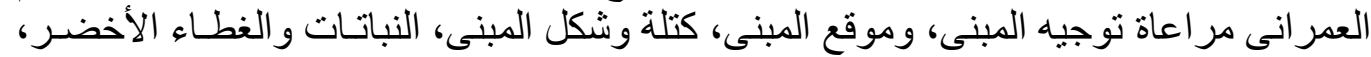

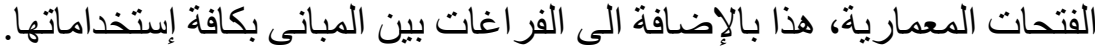

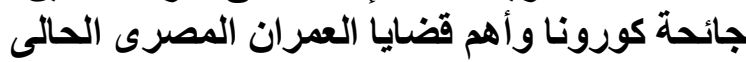

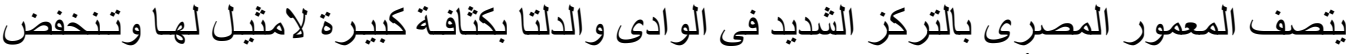

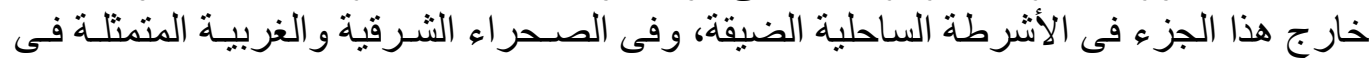

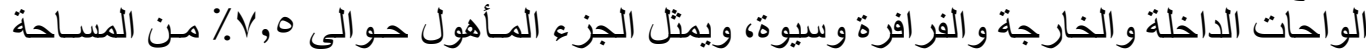

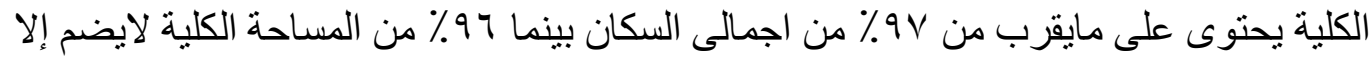

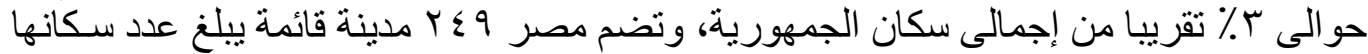

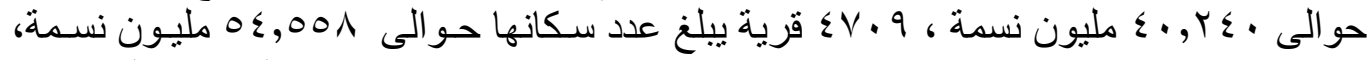

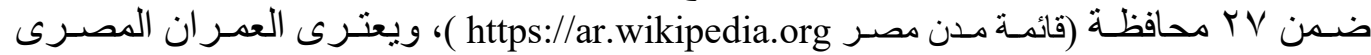

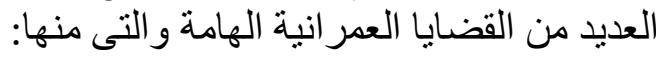

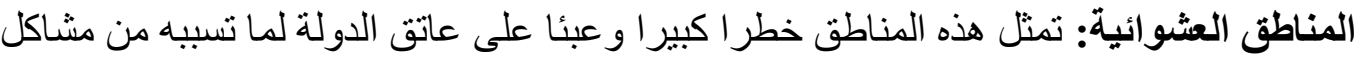

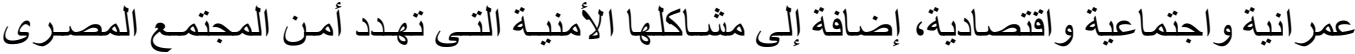

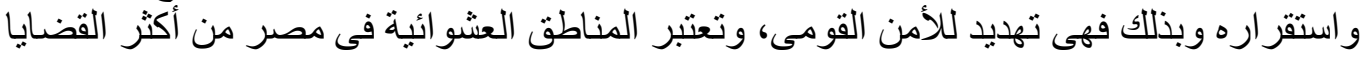

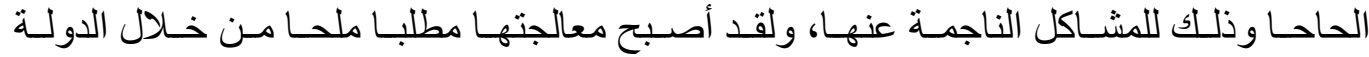

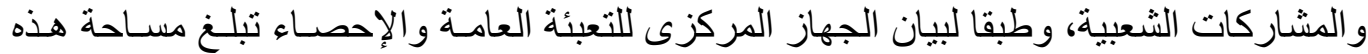

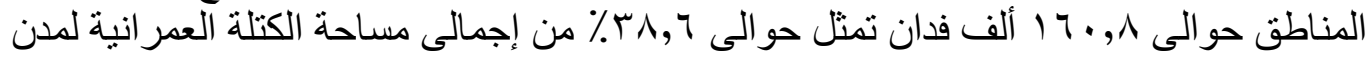

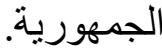




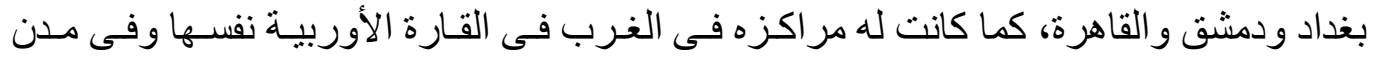

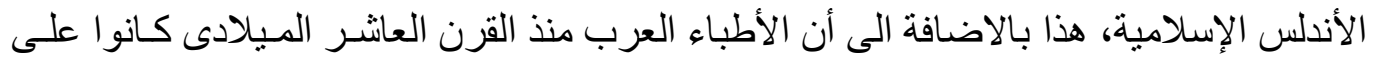

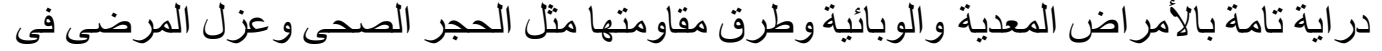

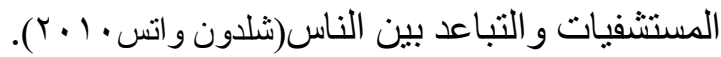
مقاومة المدن للجوائح والأوبئة:

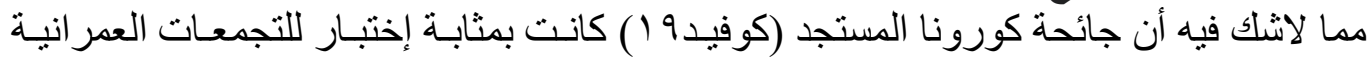

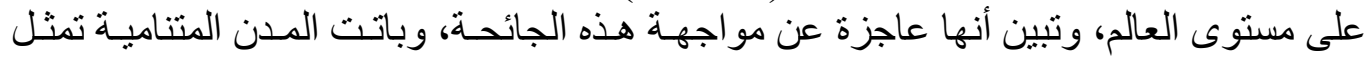

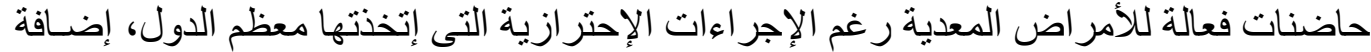

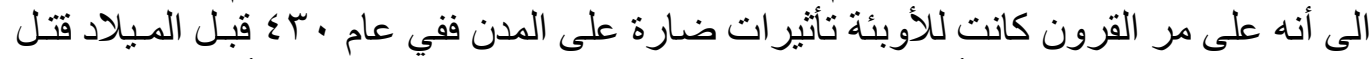

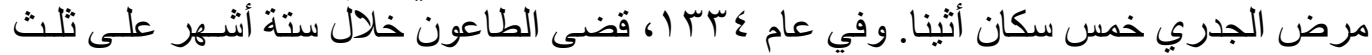

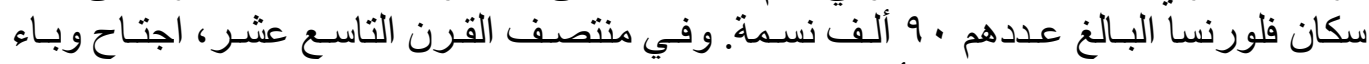

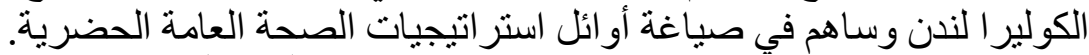

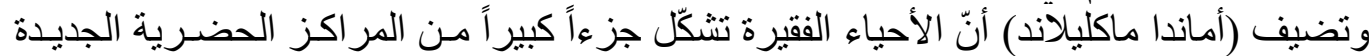

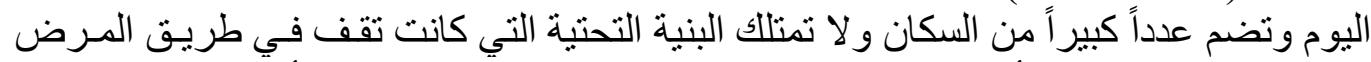

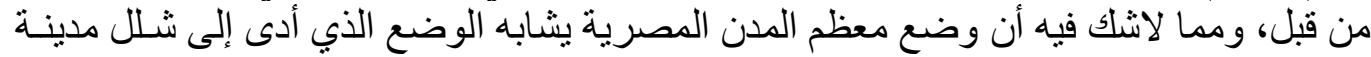

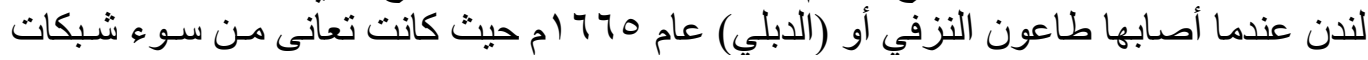

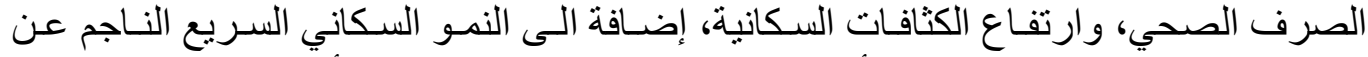

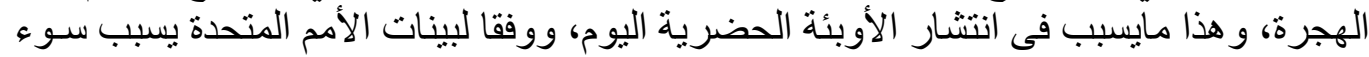

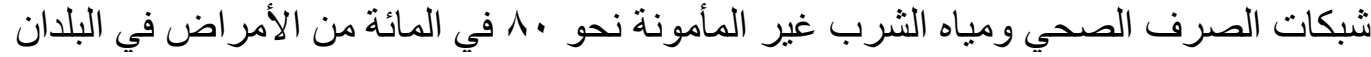

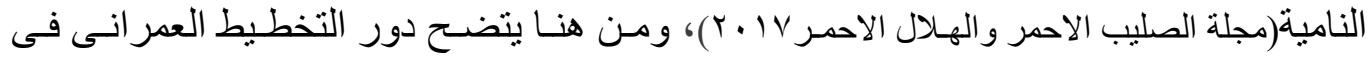

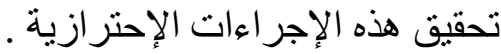

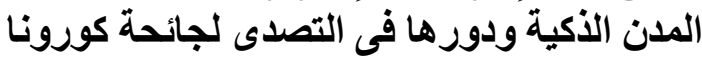

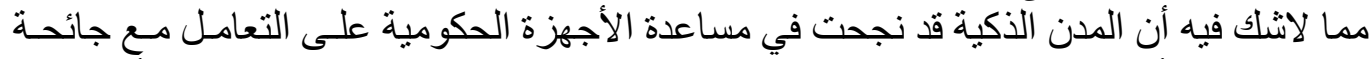

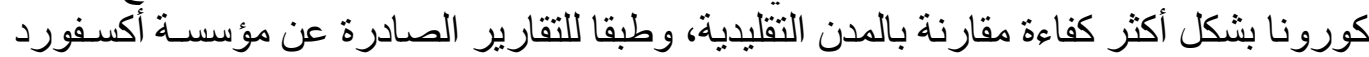

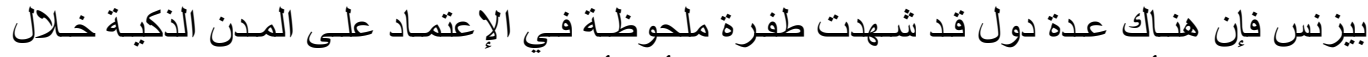

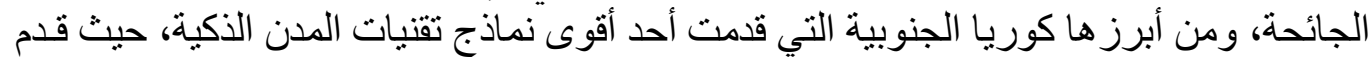

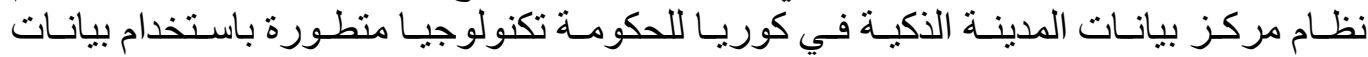

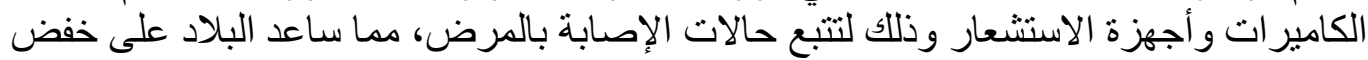

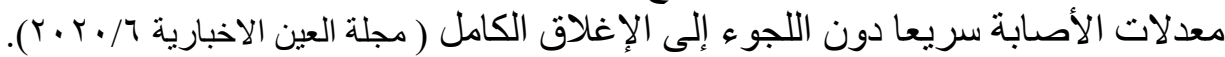

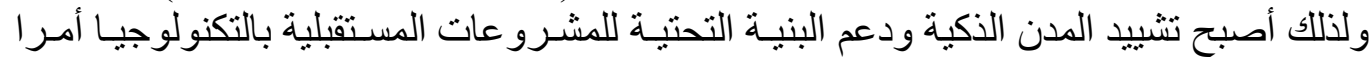

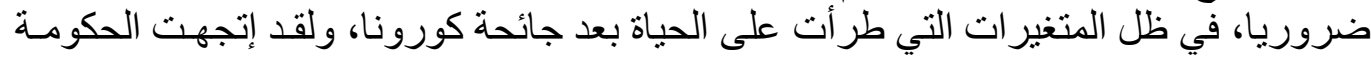

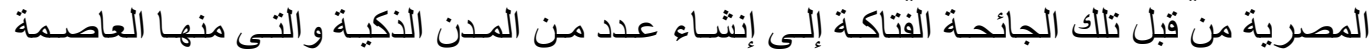

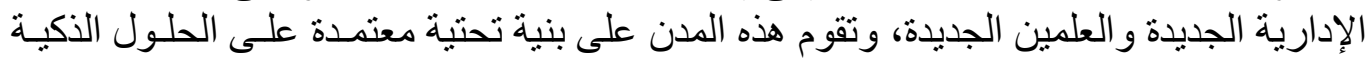

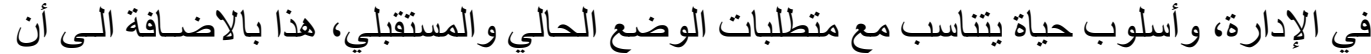

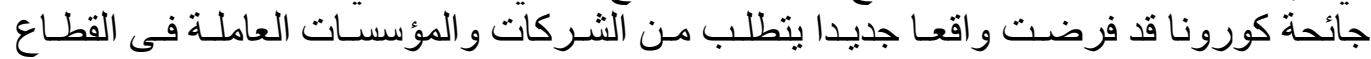

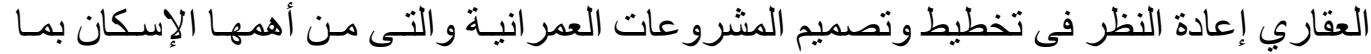
يتو افق مع المعايير التى أوصت بها منظمة الصحة العالمية(www.almasryalyoum.com5/2020).

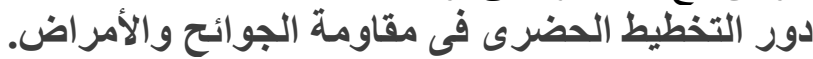

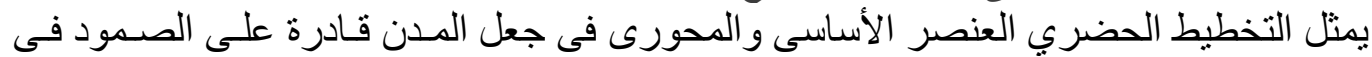

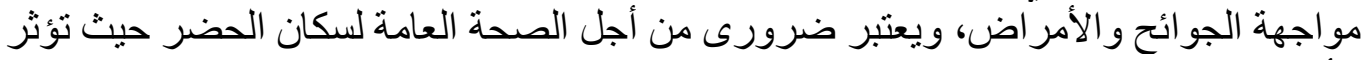

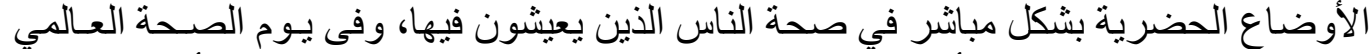

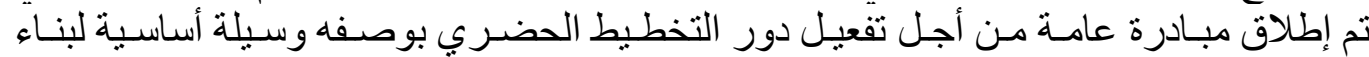
الصحة في القرن الحادي والعشرين. ولقد ناثدت منظمة الصحة العالمية الإدارات المسئولة عن 


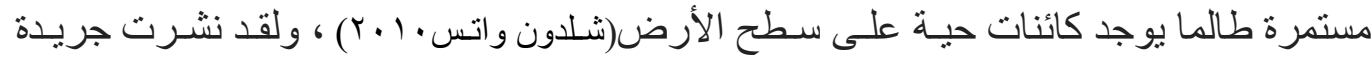

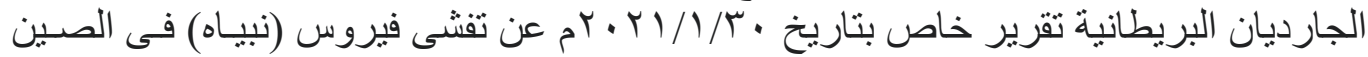

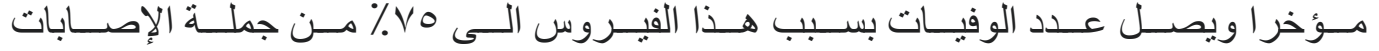

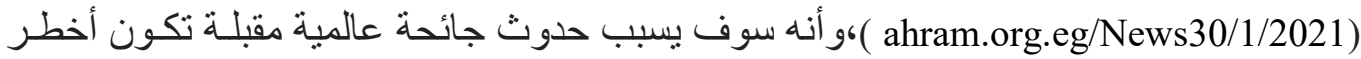

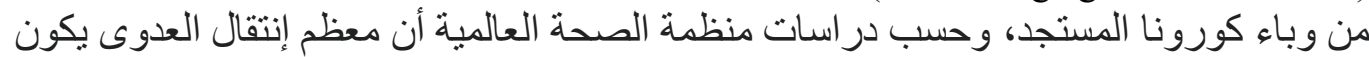

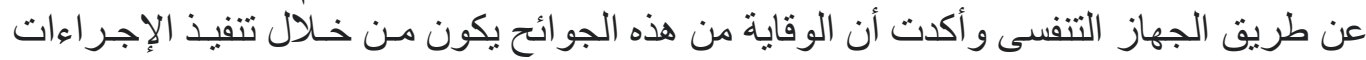

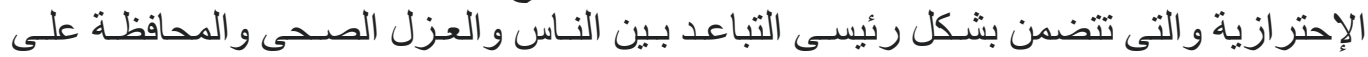

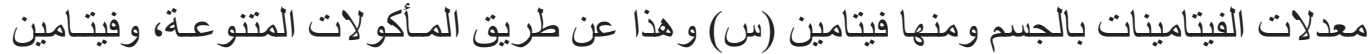

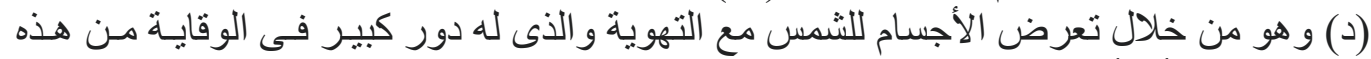

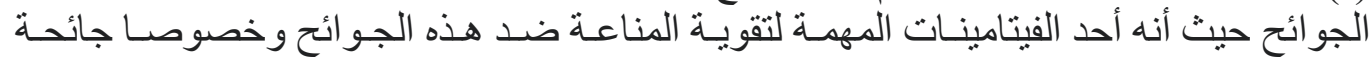

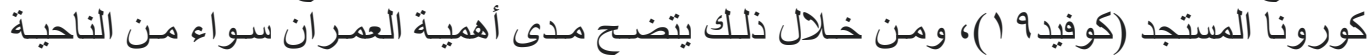

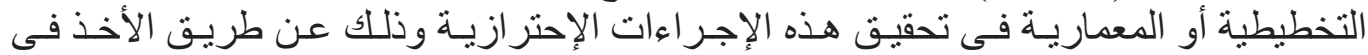

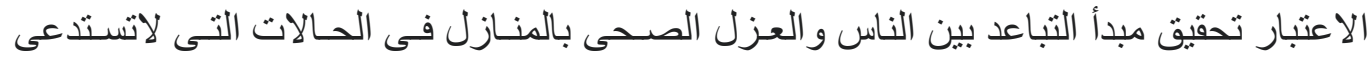

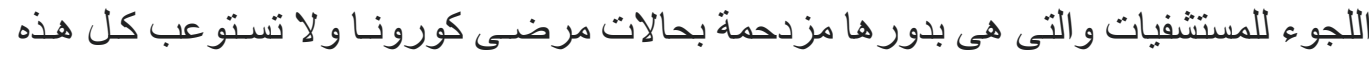

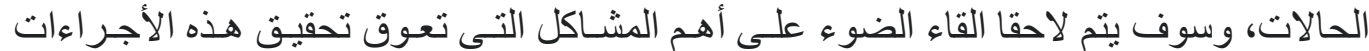

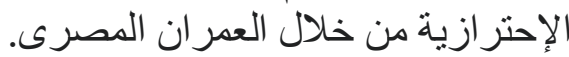

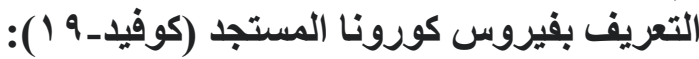

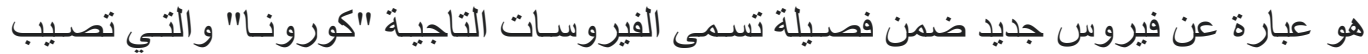

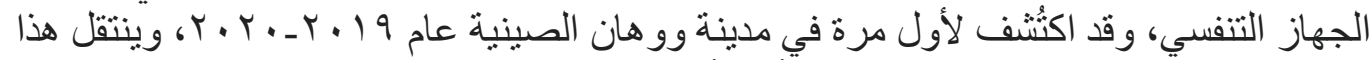

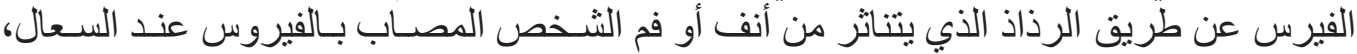

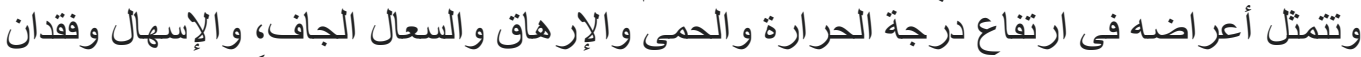

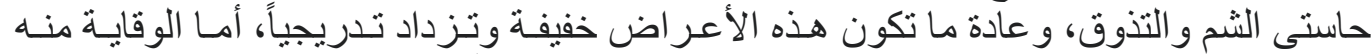

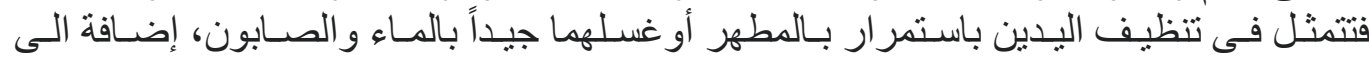

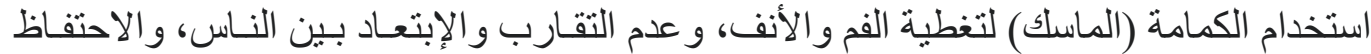

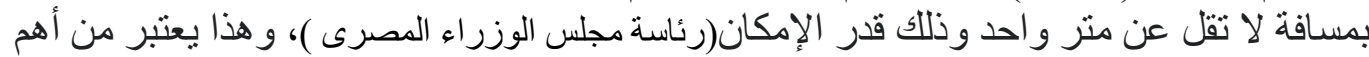

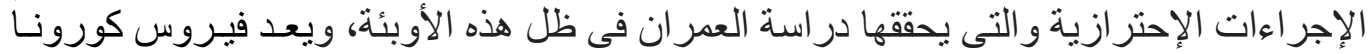
المستجد من أكبر التحديات التي تواجه العالم منذ إنتهاء الحرب العالمية الثانية، ومـع إنتشـار هذا فـا

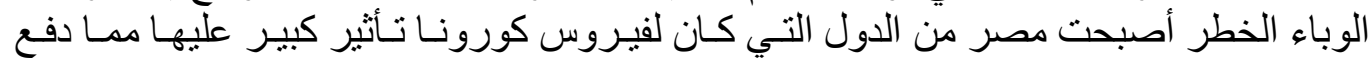

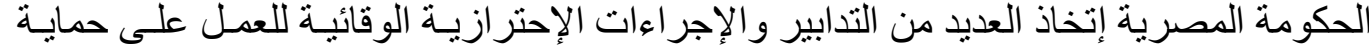

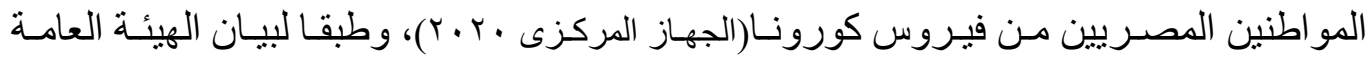

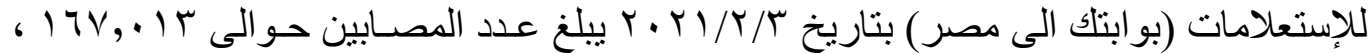

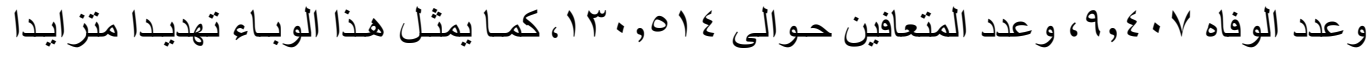

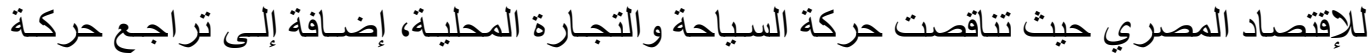

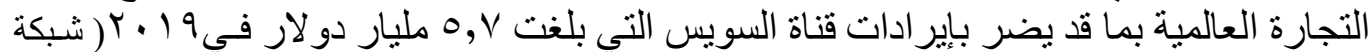

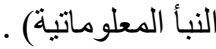

\section{الحجر الصحى ودوره في الحد من إنتشار الجوائح.}

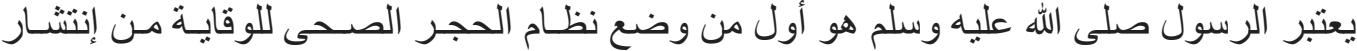

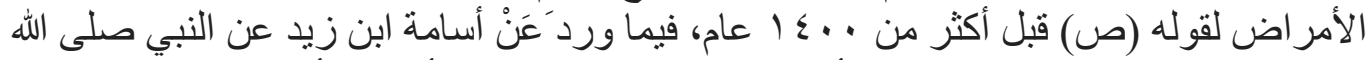

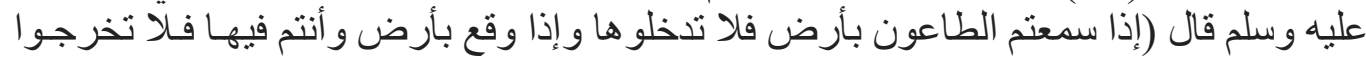

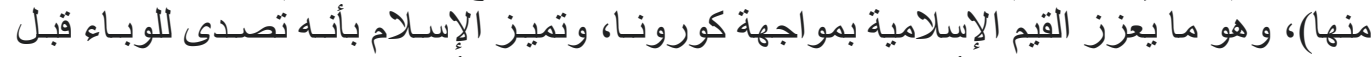

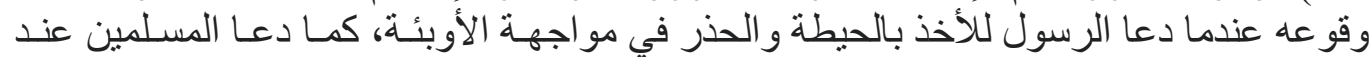

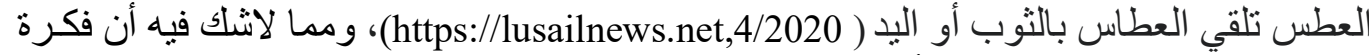
الحجر الصحى كان مصدر ها الأساسى هو الطب العربى الذى كانت له مر اكزه فـى الثـرق مثنل 
مشكلة البحث: مما لاشك فيه أن التجمعات العمر انية المصرية لم تتمتع بالمناعة الكافيـة لمو اجهـة

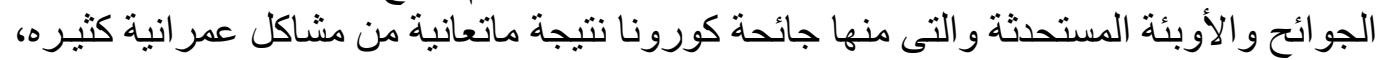
وتكمن مشكلة البحث فى كيفية الوصول إلى بعض الإستر اتيجيات التى تجعل التجمعات العمر انية التهاتية

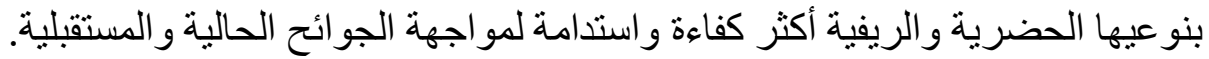

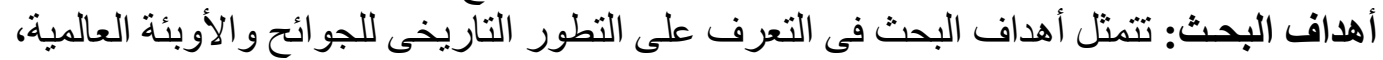

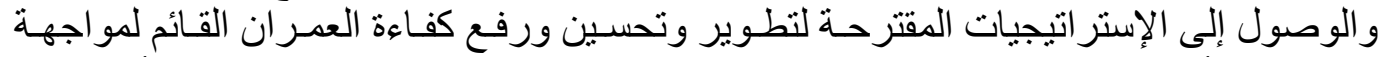

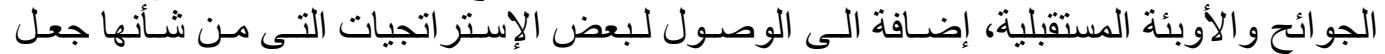

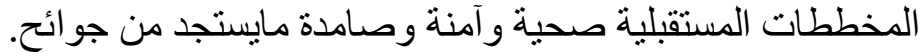

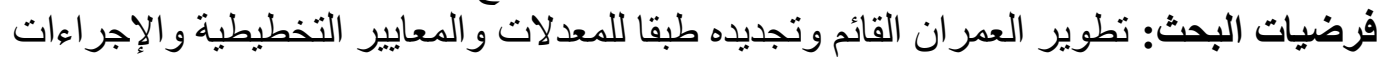

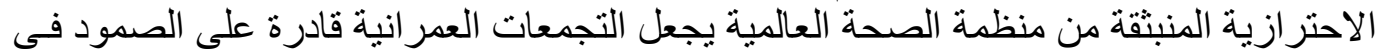
مواجهة الجو ائح و الأوبئة.

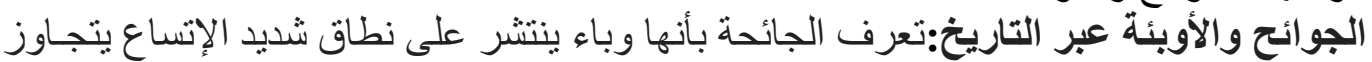

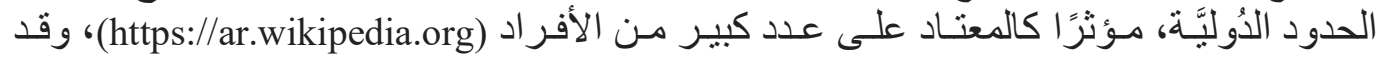

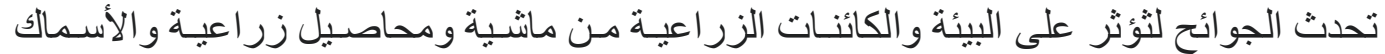

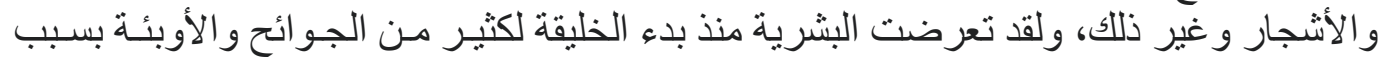

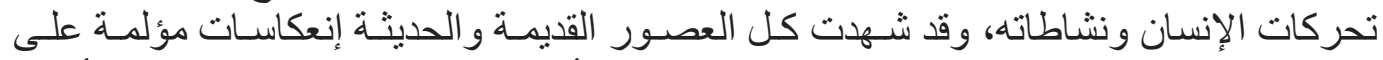

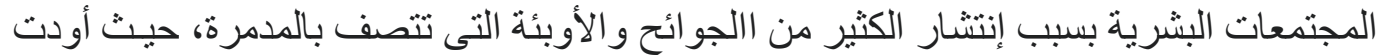

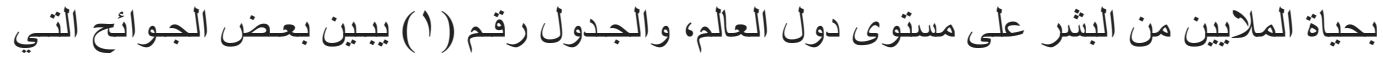
ضربت العالم منذ القرن الرابع عشر وحتى العقد الثاني من القرن الحادي والعشرون.

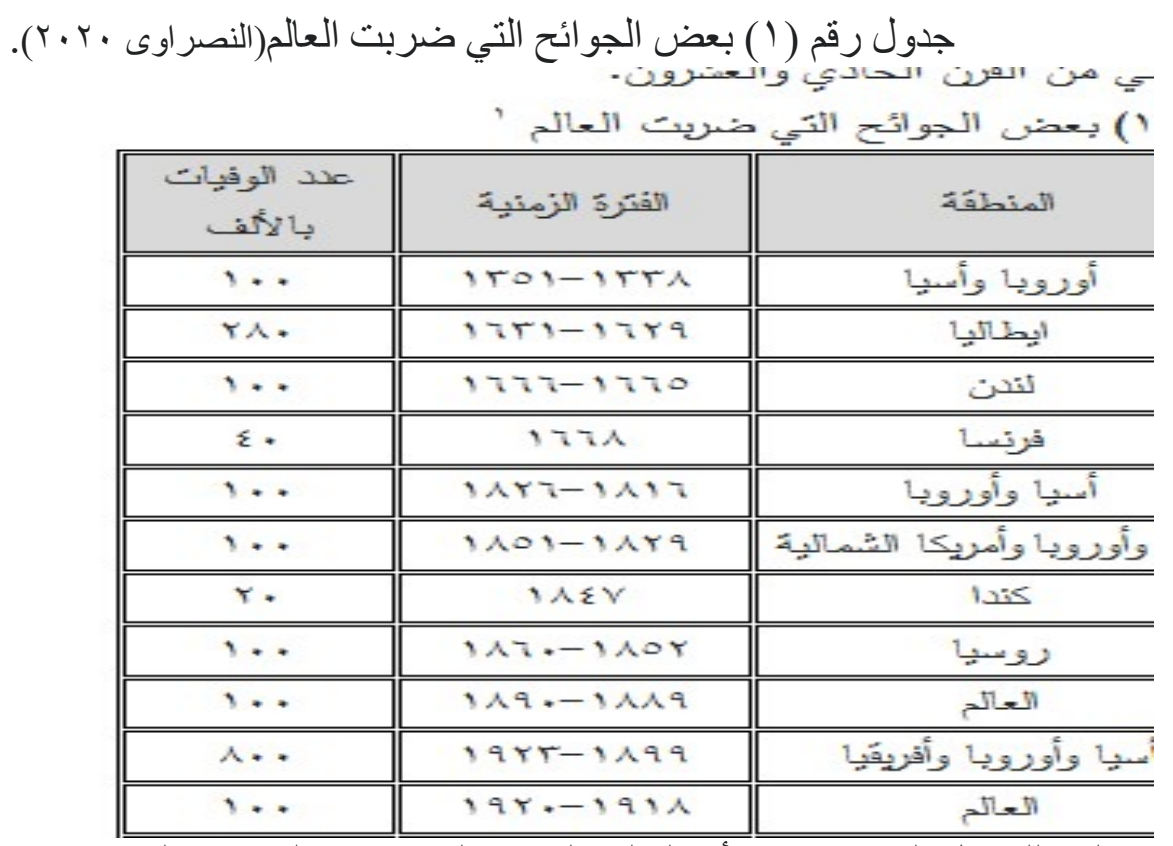

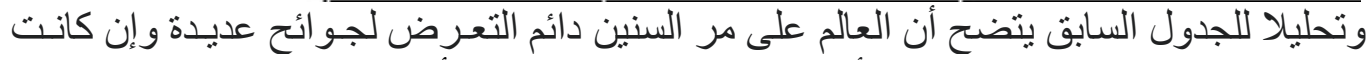

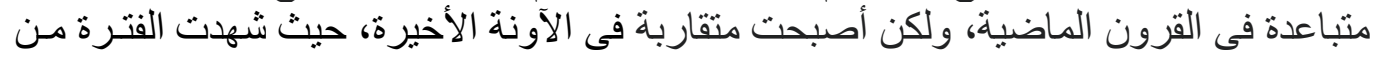

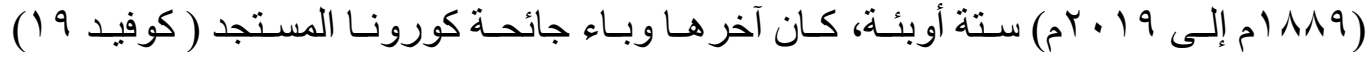

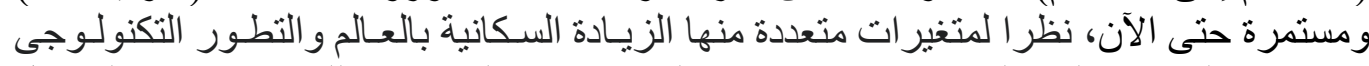

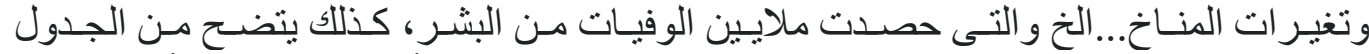
إستمر ارية الجو ائح بالعـالم، كمـا ذكر شـلدون واتس فـى (كتـاب الأوبئة و التـاريخ) أن الجـوائح 
design to ensure the creation of housing, service buildings, spaces and paths capable of protecting the health of the population.

key words: Pandemic- Novel Coronavirus (Covid 19)- Quarantine- Smart cities

\author{
جائحة فيروس كورونا المستجد ( كوفيد 1 ( ) والعمران

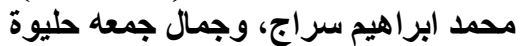

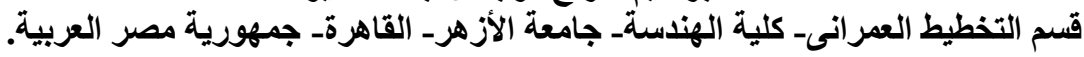

E- Mail: gamalhelewa.19@azhar.edu.eg

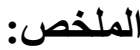

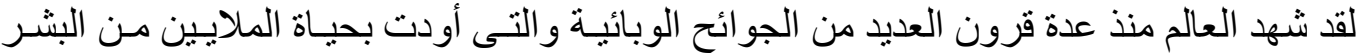

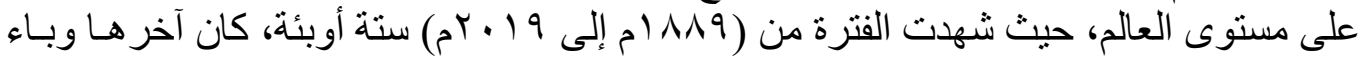

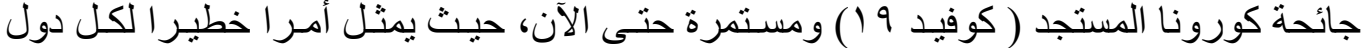

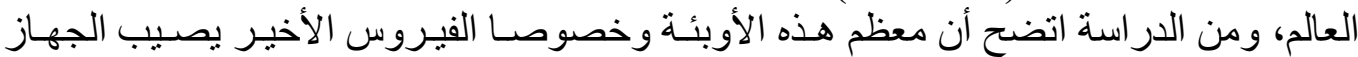

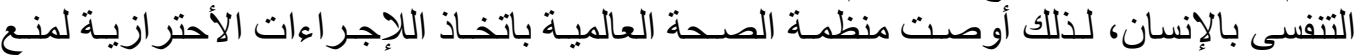

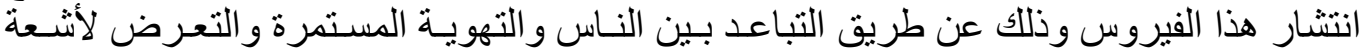

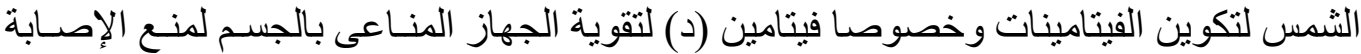

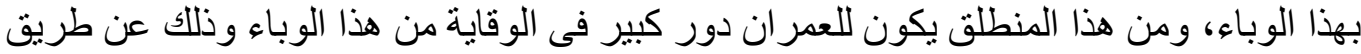

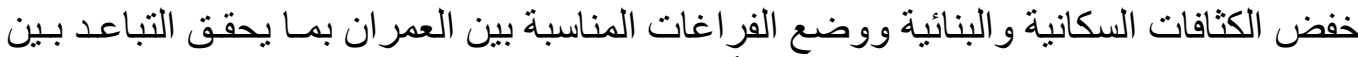
الناس مع توفير التهوية اللازمة والتعرض لأشعة الثمس مع استخدام التكنولوجيا فى إدارة المدن

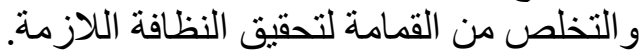

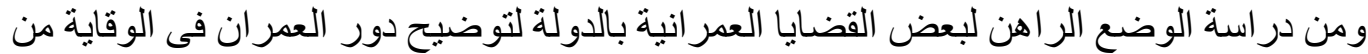

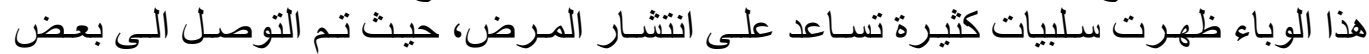

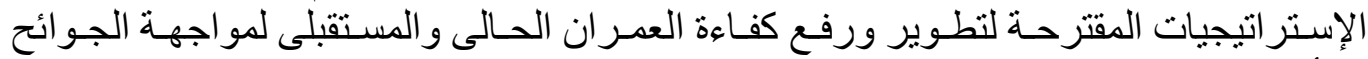

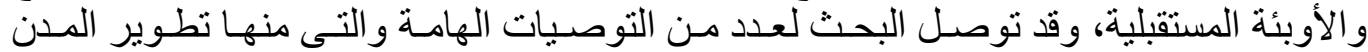

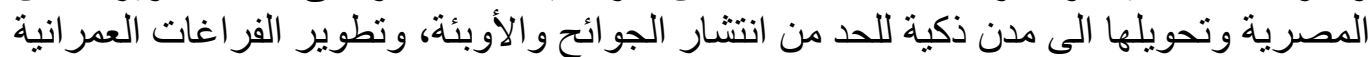

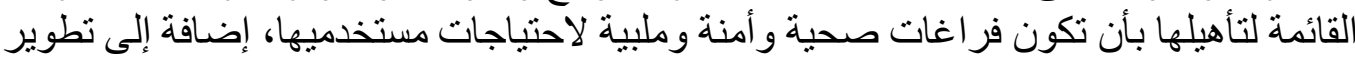

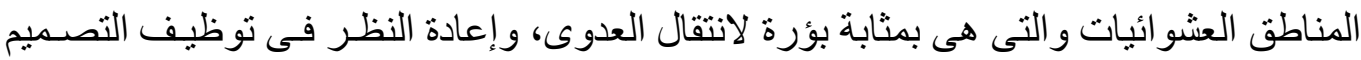

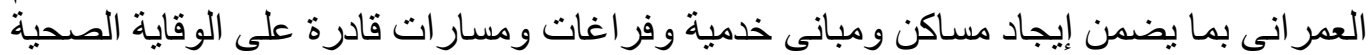
ل اللسكان.

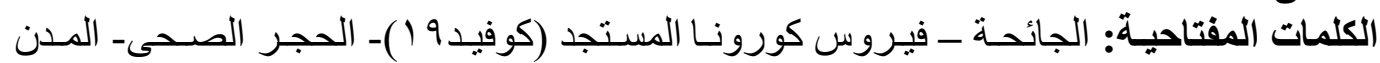
الأكية

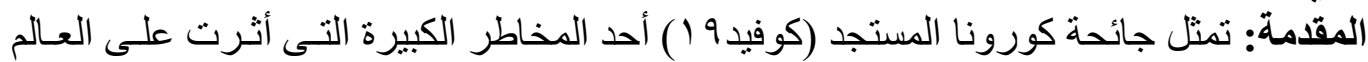

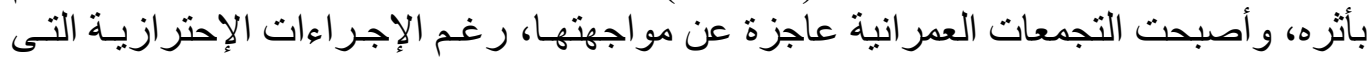

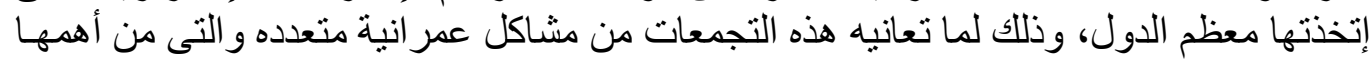

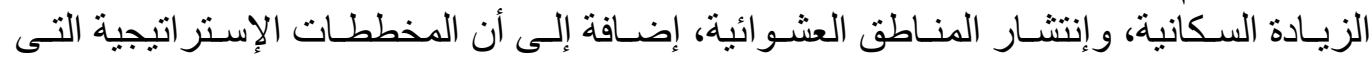

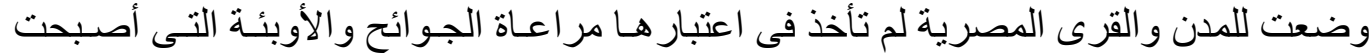

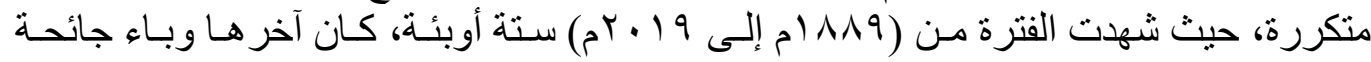

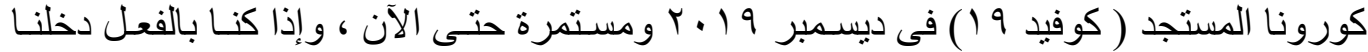

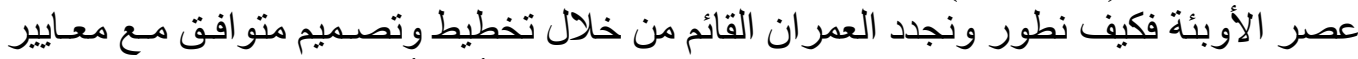

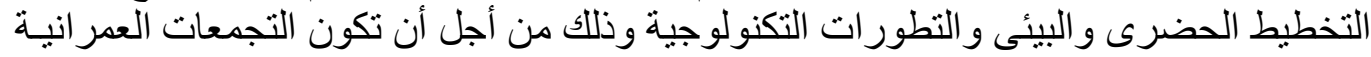

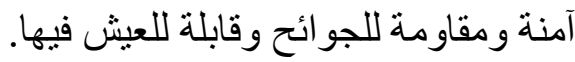


Journal of Al-Azhar University Engineering Sector

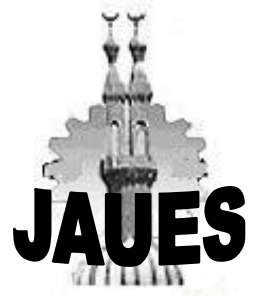

Vol.16, No. 60, July 2021, 921-933

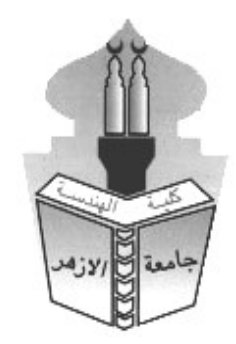

\title{
THE EMERGING CORONA VIRUS (COVID 19) AND URBANIZATION
}

Mohamed Ebrahim serag, and Gamal Gomaa Helewa

Department of urban planning, faculty of engineering, al-azhar University, Cairo, Egypt

E- Mail: gamalhelewa.19@azhar.edu.eg

Received: 13 March $2021 \quad$ Accepted: 19 April 2021

\begin{abstract}
:
Several centuries ago, the world witnessed many epidemic pandemics that claimed the lives of millions of people worldwide, as the period from (1889AD to 2019AD) witnessed six epidemics. The last of them was the new Corona pandemic (Covid 19) and continues until now, as it represents a dangerous matter for all countries of the world, and from the study it became clear that most of these epidemics, especially the last virus, infects the human respiratory system, Therefore, the World Health Organization recommended that precautionary measures be taken to prevent the spread of this virus, by spacing people, constant ventilation and exposure to sunlight to form vitamins. (D) To strengthen the body's immune system to prevent infection with this epidemic, and from this point of view urbanization has a great role in preventing this epidemic by reducing population and building densities and placing appropriate spaces between urbanization in order to achieve spacing between people while providing the necessary ventilation and exposure to sunlight with the use of Technology in city management and garbage disposal to achieve the necessary hygiene.

From studying the current situation of some urban issues in the country to clarify the role of urbanization in preventing this epidemic, many negative aspects emerged that help the spread of the disease, as some proposed strategies were reached to develop and raise the efficiency of current and future urbanization to confront future pandemics and epidemics, The research reached a number of important recommendations, including the development of Egyptian cities and their transformation into smart cities to limit the spread of pandemics and epidemics, and the development of existing urban spaces to qualify them to be healthy and safe spaces that meet the needs of their users, in addition to developing informal areas that serve as a focus for transmission of infection, and reconsidering In employing urban
\end{abstract}

